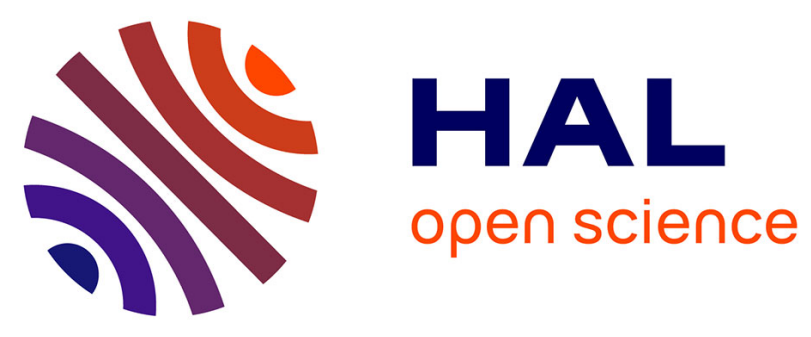

\title{
Development of a recycling solution for waste thermoset material: waste source study, comminution scheme and filler characterization
}

Fabien Bernardeau, Didier Perrin, Anne-Sophie Caro-Bretelle, Jean-Charles

Bénézet, Patrick Ienny

\section{To cite this version:}

Fabien Bernardeau, Didier Perrin, Anne-Sophie Caro-Bretelle, Jean-Charles Bénézet, Patrick Ienny. Development of a recycling solution for waste thermoset material: waste source study, comminution scheme and filler characterization. Journal of Material Cycles and Waste Management, 2018, 20 (2), pp.1320-1336. 10.1007/s10163-017-0698-x . hal-02459064

\section{HAL Id: hal-02459064 \\ https://hal.mines-ales.fr/hal-02459064}

Submitted on 7 Apr 2020

HAL is a multi-disciplinary open access archive for the deposit and dissemination of scientific research documents, whether they are published or not. The documents may come from teaching and research institutions in France or abroad, or from public or private research centers.
L'archive ouverte pluridisciplinaire HAL, est destinée au dépôt et à la diffusion de documents scientifiques de niveau recherche, publiés ou non, émanant des établissements d'enseignement et de recherche français ou étrangers, des laboratoires publics ou privés. 


\title{
Development of a recycling solution for waste thermoset material: waste source study, comminution scheme and filler characterization
}

\author{
Fabien Bernardeau ${ }^{1} \cdot$ Didier Perrin $^{1} \cdot$ Anne-Sophie Caro-Bretelle ${ }^{1} \cdot$ Jean-Charles Benezet ${ }^{1} \cdot$ Patrick lenny $^{1}$
}

\begin{abstract}
End of life electrical equipment is a continuously increasing source of waste in our modern society, and constitute an envi-ronmental problem. Understanding this type of waste flow is important to devise proper dismantlement and sorting strategies, and to maximize the material recovery rate and valorization. In this work, a waste pool constituted of electrical meter was studied. The specificities of this equipment in term of design were enlightened, and the overall material composition was determined. An emphasis was put on the characterization of the plastic fraction, both in term of plastic type and presence of regulated substances. It revealed that this fraction is mostly composed of phenolic molding compound (PMC), a thermoset material, which is troublesome in term of recycling. A material valorization solution through mechanical recycling is pro-posed, consisting in using PMC as functional filler in a thermoplastic matrix. A comminution scheme to obtain such filler is presented in this work, and the comminuted products are characterized. Through 2 or 3 steps of comminution, particle size below $50 \mu \mathrm{m}$ can be obtained, which is expected to be a sufficient size for incorporation in a thermoplastic matrix.
\end{abstract}

Keywords Recycling $\cdot$ WEEE $\cdot$ Phenolic molding compound $\cdot$ Particle size distribution $\cdot$ Comminution

\section{Introduction}

Waste management have become a subject of increasing concerns and focus over the past decades. Indeed, with the increase of worldwide population, associated with rise of good consumption, the amount of waste generated is increasing constantly. As well as that, increasing demands in goods and equipment lead to higher natural resources use. These two facts put serious stress on the environment, as inadequate waste disposal (landfilling, incineration) generates pollution and natural resources depletion affects ecosystem and will be a problem for future generations. Regulations promoting end of life (EOL) products valorisation have been enforced in Europe since the 1990 to reduce the amount of landfilled waste. They are generally based on the

Didier Perrin

didier.perrin@mines-ales.fr

http://c2ma.mines-ales.fr

1 C2MA, Ecole des Mines d'Alès, 6 avenue de Clavières, 30319 Ales Cedex, France specification of quota for recycling/reuse and for thermal valorisation. Landfilling should be minimized. They are product type specific. One example of such regulation is the end of life vehicle (ELV) directive, which impose $85 \%_{w}$ of recycling or reuse, and $95 \%$ of valorisation for automotive. This type of product represents a waste stream of 1.5 million tonnes in France each year [1].

Another important regulation is the directive "Waste of electrical and electronic equipment" (WEEE) [2]. Indeed, production of electrical and electronic equipment (EEE) is currently one of the fastest growing industry [3]. Because of their low life expectancy, they generate an increasing waste stream. For example, in France, 1.68 MT of EEE were put on the market in 2015 [4]. That is a $7.1 \%$ growth in comparison with 2014. The amount of WEEE collected in 2015 exceeded $600 \mathrm{kT}(+17.8 \%$ in comparison with 2014) [4]. In response to the environmental threat posed by this new type of waste, quota for reuse, recycling and valorisation were enforced [2]. Ten categories of EEE were defined (small household appliances, IT and telecommunications equipment, lighting equipment, etc.), with specifics quotas for each. In 2015, the maximum non-valorised fraction (ending in landfill or incineration without 
energy recovery) should not exceed $20-30 \%$ of total waste, depending on the type of equipment.

A lot of research works have been dedicated to the recycling of WEEE. Many topics have been covered, including the environmental impact and soundness of WEEE recycling [5], optimisation of collection [6], study of national of global waste flow [6-8], or modeling of local/global recycling systems from economical and/or environmental perspectives $[9,10]$. While these works consider WEEE recycling from a general perspective, many papers deal with very specific aspects of WEEE recycling, such as material analysis and quantification in specific equipment or waste flows [11-16], or optimization of dismantling operations [17-25]. Material analysis is an important step for designing recycling strategies, as it defines valuable materials which can be recovered (which allow, for example, calculation of potential revenue from recycling the equipment), and potentially hazardous materials which should be isolated (such as lead, mercury, etc.) as defined by relevant legislation.

Different methods can be used to assess the material composition of equipment. The most straightforward and exact method for material composition analysis is manual dismantlement and material sorting. While it gives the exact composition of the considered equipment, the results cannot be necessarily extrapolated. Indeed, WEEE stream are complex and contains countless types of equipment, with very different material composition. To devise general strategies for materials sorting and recovery from dismantlement of a discreet amount of WEEE, sampling has to be carefully considered. Another way is to analyze shredded mixed samples issued from a mechanical process and automated sorting. Indeed, a very large batch of mixed WEEE can be processed this way, and particulate samples collected after shredding can have a better representability of the material composition of highly heterogeneous WEEE batch. While a better representability can be obtained with this method, the exact material composition might not be determined. Indeed, complete material separation is usually not achieved through shredding, and automated material sorting is not perfect. The material composition of WEEE stream deduced through this process is highly dependent on the process efficiency itself.

While recycling technologies for metallic or glass fraction have been implemented a long time ago, mechanical recycling of plastics is still not fully developed. On one hand, thermoplastics, which represent $80 \%$ of all plastics materials, are technologically recyclable because of their fusible nature. On the other hand, mechanical recycling of thermoset and elastomeric material is trickier, because of their reticulate structure and their infusible nature. One example of thermoset material is phenolic molding compound (PMC), also known as Bakelite ${ }^{\mathrm{TM}}$, which is a resin based on phenol and formaldehyde condensation.
For this type of thermoset plastic, mechanical recycling generally consists in comminuting the material and incorporating in a matrix (same material or different). Most of the literature works focus on fiber-reinforced thermoset, where the main goal is to recover the fibrous fraction (glass or carbon fiber). Such approach has been used to recycle woven glass phenolic laminates with a glass content of $80 \%$ [26-28]. Through a specific comminution scheme and coupling strategies of the filler with the polypropylene matrix, composites with better tensile and impact properties than the matrix were produced. It was shown that incorporation of phenolic prepreg (70\% glass fiber) in polypropylene increased drastically its thermo-oxidative stability and mechanical properties after accelerated aging [29].

The mechanical recycling of non-fiber filled phenolic thermoset was investigated to a lesser extent. Incorporation of comminuted PMC into virgin phenolic resin has been proposed [30]. It led to recycled material with equal or lesser mechanical properties than virgin material. Mineral-reinforced PMC has also been incorporated in polypropylene thermoplastic matrix [31]. With rather large micronized particles (median particles size superior to $420 \mu \mathrm{m}$ ), an important decrease of tensile strength with increasing fraction of filler was observed, probably linked to poor adhesion between filler and matrix.

Apart from recycling consideration, addition of uncured phenolic resin in polypropylene was also studied [32, 33]. At polypropylene processing temperature, curing of phenolic resin occurred under shearing condition. This led to the development of bi-phasic microstructure, with cured phenolic nodules of micronic or sub-micronic sizes within the continuous PP matrix. Good adhesion between the phenolic nodules and the matrix was achieved using coupling agent. In these conditions, significant improvement of the mechanical properties (Young modulus, tensile strength, Izod impact strength) of the PP matrix was observed.

These works on PMC-filled plastic show that particle size distribution is an important parameter, which has a significant impact on mechanical properties. This fact is more generally observed in thermoplastic filled with rigid fillers [34-36]. A decrease in particle size is usually associated with an increase in composite mechanical properties, in particular its tensile and impact strength. Significant increase in strength is generally obtained with particles below $100 \mathrm{~nm}$ in size, which is difficult to obtain by comminution. Low dispersion in particle size distribution is generally recommended, as big particles decreases mechanical strength, and small particles tends to agglomerates, which is also detrimental to mechanical properties [35]. Commercial mineral fillers (such as $\mathrm{CaCO}_{3}$, talc, mica, and clays) have particle size distribution generally between these boundaries, and typically in the $1-40 \mu \mathrm{m}$ range [37]. While control of PMC recyclate properties such as PSD might improve 
processability and mechanical properties of prepared composites, and allows substitution of traditional mineral filler, it does not fully justify this valorization scheme from an industrial point of view. Indeed, mineral fillers are very cheap, and are often used to decrease the price of the material. Other advantages of using PMC filler can be proposed. For example, phenolic resin is used as a synergist agent in the formulation of flame retardant package for various thermoplastics [38-42]. These additives are very costly, and using PMC waste as synergist in such package could have economical advantage. As previously mentioned, antioxidant effect has also been reported. Additional properties brought by the PMC waste can shift the paradigm from low cost filler to functional filler.

To obtain PMC in this size range for incorporation in a thermoplastic matrix, a comminution scheme has to be studied. Several works have been published on this topic in the literature. Comminution of fiber-reinforced thermoset has been studied and is nowadays an industrial reality. For this type of material, the emphasis is not put on severe size reduction into the microns range, but on recovery of undamaged fiber with the highest length and highest degree of separation from the matrix and fillers possible [43-45]. Mild shredding conditions are used, typically with cutter mill. Comminution to very fine size of other plastics has also been considered to some extent [46-53]. For most plastics, cryogenic milling is used, because of their ductile nature at room temperature [46-48, 52]. However, for brittle polymer with glass transition above room temperature, significant size reduction can be achieved without cooling [49-51,53]. This is the case for polystyrene or poly(vinyl acetate). Particle sizes below $40 \mu \mathrm{m}$ were achieved after various time of grinding (up to $24 \mathrm{~h}$ ). Ball milling is the most used comminution equipment. However, in comparison with other materials such as mineral ore, the available data on plastic comminution (comparison of grinding technic, effect of comminution time on particle size, energy efficiency of process) are very scarce.

In this work, a particular type of waste stream in France is studied, which is constituted of electric meters (EM). It is associated with several peculiarities. First, it is a finite waste stream, with a quantifiable and slowly changing number of appliances (about 35 million units). While most waste streams are directly linked with goods and equipment consumption, and fluctuate in time depending on economical conjuncture, development of new products and innovation, new trends in consumption, etc., this EM waste stream increases very slowly. The growth is only linked to the number of household, company and electricity consuming building ( 1 electric meter per electricity consuming unit). For comparison, the growth of WEEE is linked to number of household/company/consumer but also to number of EEE per household/consumer, which is in constant growth (99 appliances per household in 2015 in France, including light bulbs [4]). The second peculiarity of electric meters is their lifespan. These appliances were designed for decades of service life, thus electric meter dating from the 50' are still present in the stream. In comparison, the lifespan of EEE is in the range of a few years, and is constantly decreasing. In the US, the lifespan of personal computer decreased from 4.5 years in 1992 to 2 years in 2006 [54]. This, in combination with constant evolution in EEE design, leads to a constantly evolving waste stream in terms of material composition. On the contrary, the EM stream is almost fixed and reflects the evolution of design and the complexity and heterogeneity of materials used over half a century period. This heterogeneity might be dampened down by the last peculiarity, related to the low rate of renew in EM design. Less than 150 models of EM have been produced and installed over this period, which is low in comparison with other types of equipment, such cell phone, computer, etc.

A characterization of this EM waste stream is proposed in this work. Materials, assembly analysis and quantification are performed through manual dismantlement and sorting. Because of the peculiarities of this waste stream, a statistical approach based on the determination of the abundancy of each models of EM and their material composition allowed to calculate the overall material composition of the stream. Based on these data, general recycling strategies are also discussed. It appeared that most of the plastics of the stream are composed of a thermoset material, a phenolic molding compound (PMC). This plastic is troublesome in terms of recycling. To increase the overall recyclable fraction of the stream, a solution to recycle this thermoset material is proposed. It consists in using the PMC as filler in a thermoplastics matrix to increase its properties (mechanical, thermal). The first step to transform PMC waste in usable filler is comminution to the appropriate size, which should necessary be below $500 \mu \mathrm{m}$. As reduction of filler size to microns size range usually results in increasing mechanical properties of the composites, even finer particles size are preferable. Therefore, several comminution schemes are evaluated to obtain different particle size distributions (PSDs) with sizes from hundreds of microns to tens of microns.

\section{Materials and methods}

\section{Waste stream study}

First, the Electric Meter waste stream was studied to better understand the design of the appliances and the material composition. This equipment was produced and used over a period of 50 years (1950-2000). Because of that, many models of electric meters exist (over 100), with some difference in design and in the materials used. The stream 
analysis scheme was designed to retrieve useful information to implement recycling strategies. It was constituted of different steps (Fig. 1). An emphasis was put in the last part on the extraction and characterization of hardly recyclable material such as PMC, which lower the overall recyclable fraction of the stream.

To get a general understanding of the stream, a sample of 130 electrical meters of all kinds were first studied. For each model of electric meter, a reference number was assigned (EM1, EM2, ..., EMn), with $n$ the total number of EM models, and the year in which it came in use was recorded. The number of each model of electrical meter in the sample was counted $\left(N_{\mathrm{EM} 1}, N_{\mathrm{EM} 2}, \ldots, N_{\mathrm{EMn}}\right)$. One of each kind was then weighted $\left(M_{\mathrm{EM} 1}, M_{\mathrm{EM} 2}, \ldots, M_{\mathrm{EMn}}\right)$. From these data, it was possible to establish different mass balances to better understand the stream. The number and mass fraction $\left[\mathrm{F}_{\text {number }}(\mathrm{EMx})\right.$ and $F_{\text {mass }}(\mathrm{EMx})$, respectively] of every electrical meters model in the samples was calculated (Eqs. 1, 2). From a visual standpoint, it was possible to classify EM in 3 types, according to their casing materials: metal casing EM (a), black plastic or blue-painted plastic casing (b), and white plastic casing (c) (Fig. 2).

$$
\begin{aligned}
& F_{\text {number }}(\mathrm{EMx})=\frac{N_{\mathrm{EMx}}}{\sum_{k=1}^{n} N_{\mathrm{EMk}}} ; x=1 \ldots n, \\
& F_{\text {mass }}(\mathrm{EMx})=\frac{N_{\mathrm{EMx}} \times M_{\mathrm{EMx}}}{\sum_{k=1}^{n}\left(N_{\mathrm{EMk}} \times M_{\mathrm{EMk}}\right)} ; x=1 \ldots n .
\end{aligned}
$$

Fig. 1 Sorting and identification scheme of plastics and PMC part in electric meter sample

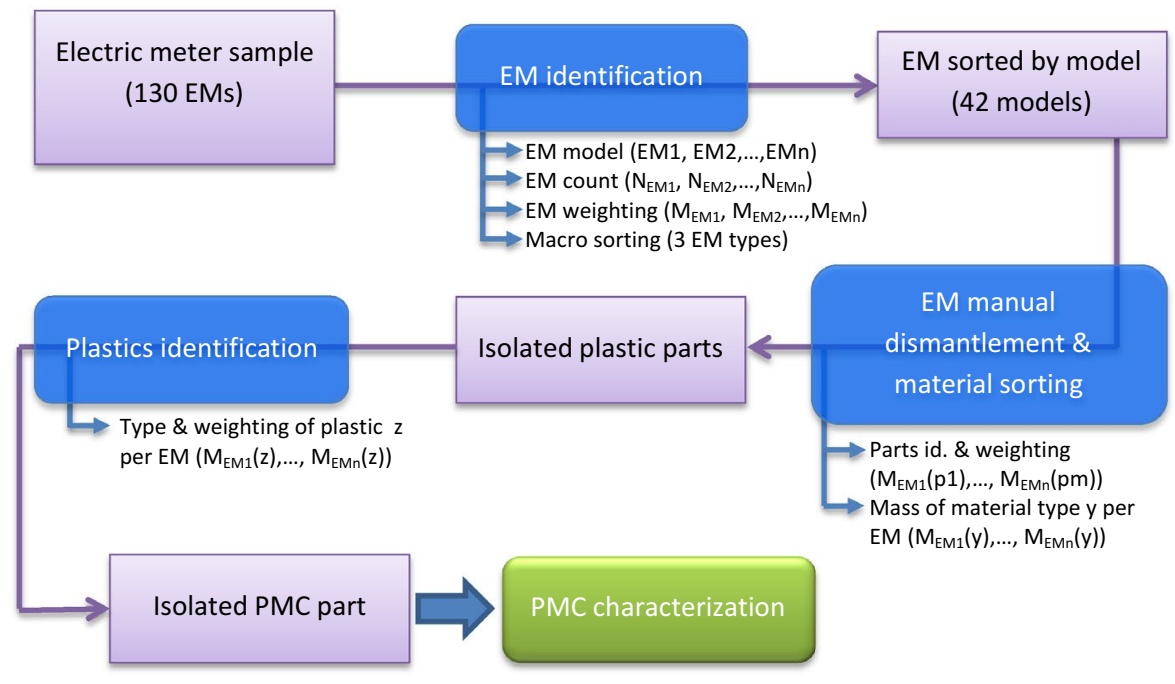

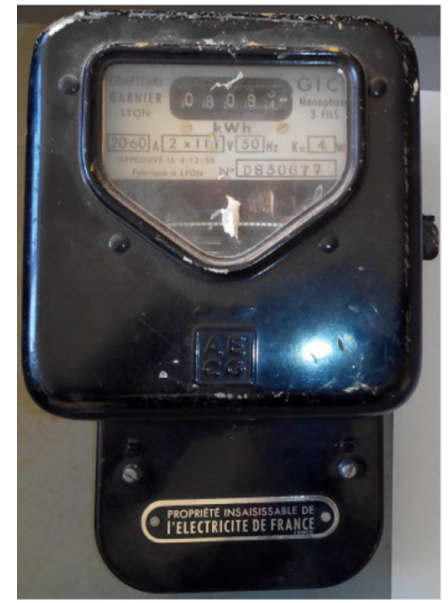

(a) Metal casing EM

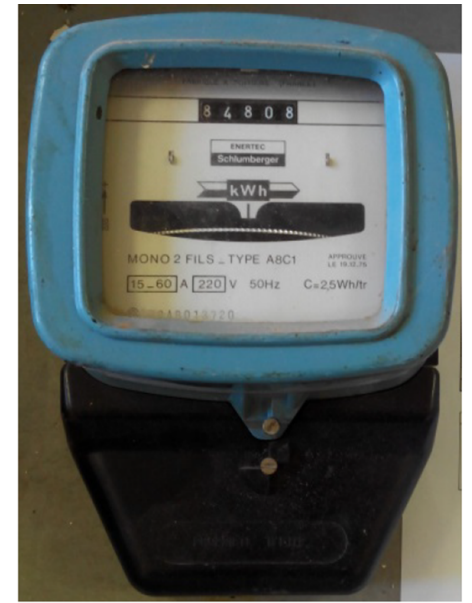

(b) Black plastic/blue painted plastic casing EM

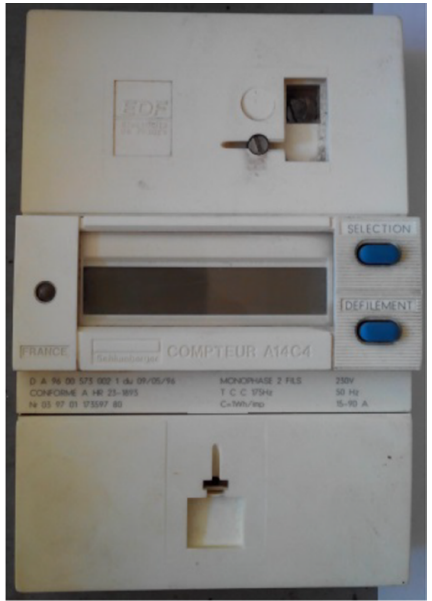

(c) White plastic casing EM

Fig. 2 The 3 main identified types of electrical meters 
Electric meters were then manually disassembled to isolate parts constituted of single materials. It was not always possible to fully separate materials; some parts were recovered as assemblies made of several materials (printed card board, coils, mixed). All parts and assemblies were referenced and weighted $\left[M_{\mathrm{EM} 1}(\mathrm{p} 1), M_{\mathrm{EM} 1}(\mathrm{p} 2), \ldots, M_{\mathrm{EMn}}(\mathrm{pm})\right]$. Eight types of materials and assemblies were identified in these parts: ferrous (Fe), mixed non-ferrous (No-Fe), plastic $(\mathrm{Pl})$, glass $(\mathrm{Gl})$, printed card board (PCB), wires (Wi), coils (Co), and mixed (Mi). Differentiation of materials was made on a visual basis, and ferrous and non-ferrous metal were sorted with a magnet. The mixed type consisted of mixed materials (ferrous and non-ferrous metal, coil, plastics) which could not be separated and could not be valorized as an assembly. For each electrical meter model, the total mass of each material was calculated $\left[M_{\mathrm{EM} 1}(\mathrm{Fe}), M_{\mathrm{EM} 1}(\mathrm{No}-\right.$ $\left.\mathrm{Fe}), \ldots, M_{\mathrm{EMn}}(\mathrm{Mi})\right]$. From these data, the total mass fraction of every material (mat) in the sample and in each EM type was calculated (Eq. 3),

$F(\mathrm{mat})=\frac{\sum_{k} N_{\mathrm{EMk}} \times M_{\mathrm{EMk}}(\mathrm{mat})}{\sum_{k} N_{\mathrm{EMk}} \times M_{\mathrm{EMk}}}=\sum_{k}\left[F_{\mathrm{mass}}(\mathrm{EMk}) \times \frac{M_{\mathrm{EMk}}(\mathrm{mat})}{M_{\mathrm{EMk}}}\right]$,

where mat $=\mathrm{Fe}, \mathrm{No}-\mathrm{Fe}, \mathrm{Pl}, \mathrm{Gl}, \mathrm{PCB}, \mathrm{Wi}, \mathrm{Co}$ and $\mathrm{Mi} ; k$ corresponds to all models for mass fraction calculation in the sample, or only models of a given type.

\section{Plastic material characterization}

A Bruker IFS66 FTIR in ATR (Attenuated Total Reflectance) mode was used to analyze dismantled plastic parts. Samples IR spectra were compared to common plastics spectra from a database for identification. Less than $2 \%{ }_{\mathrm{w}}$ of the plastic samples could not be identified. The mass fraction of each plastic type in the whole sample or in the plastic fraction was calculated with Eq. 3 .

An elemental analysis of all PMC and white plastics has been performed first to assess the presence of harmful or regulated substances in the formulations. A XMET5100 portative $\mathrm{X}$ ray fluorescence analyzer has been used. Flat samples (surfaces from 4 to $6 \mathrm{~cm}^{2}$ ) rinsed with ethanol have been analyzed. Since no calibration method has been used, only qualitative results were obtained.

SEM and EDX analysis have been performed to specify the type and the amount of fillers in plastics, as well as regulated substances. A FEI Quanta 200 FEG ESEM equipped with an X-Max 80 EDX module was used. Freshly fractured samples were analyzed after coating with carbon to increase their electrical conductivity. For elemental composition determination by EDX, surfaces of about $1 \mathrm{~mm}^{2}$ were analyzed. Elemental composition of individual filler particles was also analyzed.
Densities of PMC have been measured by weighting 10 specimens of 80 by $10 \mathrm{~mm}$. Flexural and Charpy impact properties were measured on 80 by $10 \mathrm{~mm}$ coupons. For flexural testing, a Zwick Z010 equipped with a $10 \mathrm{kN}$ load cell and a three-point bending set-up was used. Tests were carried according to ISO 178, with 5 samples tested for each formulation. Charpy impact strength was measured with a Zwick 5102 on unnotched samples in standing position.

\section{Comminution equipment}

Three comminution processes were used in this study: a knife mill to grind PMC to particles of millimeter size, a disk mill and a ball mill to micronize grinded product.

To prepare the PMC waste, all contaminants (metal insert, paper) were separated manually from the parts using tools when necessary (such as screwdriver, saw). A precrushing was done with a jaw crusher to reduce the pieces to an appropriate size ( $<5 \mathrm{~cm}$ in length and width, $2-4 \mathrm{~mm}$ in thickness) for further comminution. The pre-crushed parts were washed two times in water to remove dust and remaining contaminants, and then they were dried for $24 \mathrm{~h}$ at $80^{\circ} \mathrm{C}$.

During the first step (coarse grinding), PMC pieces were introduced in the knife mill (Retsch SM300) at a $5 \mathrm{~kg} / \mathrm{h}$ feeding rate. The effect of two parameters on the size of crushed products was studied:

- The size of the grid: 4, 6 and $8 \mathrm{~mm}$ grid

- The rotation speed of the knife: 1000, 1500 and $2000 \mathrm{rpm}$.

The crushed product was then micronized with a disk mill (Pallmann PPL18). A feeding rate of $5.5 \mathrm{~kg} / \mathrm{h}$ was used. The rotation speed of the percussion disk was set to $10,000 \mathrm{rpm}$. The spacing between the stationary and rotating disk, which mainly set the size of the micronized product, was varied between 1.38 and $2.48 \mathrm{~mm}$.

Two distinctive processes were applied to further reduce and tailor the PSD of micronized products. On one hand, a selection process was conducted by sieving. Four top cuts were performed with sieves (400, 200, 100 and $40 \mu \mathrm{m}$ meshes) to reduce the size of the products. A top cut consists in sieving the product and selecting the passing fraction. A top cut at $400 \mu \mathrm{m}(<400 \mu \mathrm{m})$, therefore, means a selection of all particles below $400 \mu \mathrm{m}$ in size.

On the other hand, product of size above $200 \mu \mathrm{m}$ was further micronized with a ball mill (5L jar, alumina) to assess the minimum size of particles achievable through this process and associated comminution time. Two different sets of alumina balls were used (mixture of 4 and $3.2 \mathrm{~mm}$, and mixture of 2.6 and $1.8 \mathrm{~mm}$ ) depending on the initial size of the PMC, filing in both case one-third of the volume of the jar. The same volume of PMC was 
introduced in the jar for milling. The rotational speed was about $50 \mathrm{rpm}$, which allowed cascading motion of the balls.

For each step (comminution, selection and mixing) a yield was calculated, which corresponds to the quantity of retrieved product after the operation divided by incoming amount. During comminution steps, the material loss $(100 \%$ yield) is mostly due to volatile particles extraction or materials stuck in the grinders. For selection step, the yield corresponds to the quantity of selected fraction; the material loss corresponds to the fraction with undesired size.

\section{Powder characterization}

Comminuted products were characterized by different means. The PSDs of products crushed with the knife mill were characterized by weighting fraction retained in stacks of sieves. Sieves with apertures of 6.3, 4, 3.15, 2, 1 and $0.8 \mathrm{~mm}$ were used. A vibrating column was used to fully sieve all fractions. The last passing fraction (below $0.8 \mathrm{~mm}$ ) was referred as $0 \mathrm{~mm}$ fraction.

PSDs of micronized products were characterized by laser diffraction. A Beckman Coulter LS 13320 laser diffraction particles size analyzer was used, with a Tornado Dry Powder System for PSD above $40 \mu \mathrm{m}$, and liquid module in ethanol for PSD below $40 \mu \mathrm{m}$ (obscuration: $8 \pm 1 \%$, pump speed: $30 \%)$. Each sample was measured in duplicate. Particle sizes were computed using a Fraunhofer model. Volume and cumulative volume repartitions of particle size were obtained. Some statistical parameters were used for comparing PSD, such a $d_{10}, d_{25}, d_{50}, d_{75}$ and $d_{90}\left(d_{x}\right.$ corresponds to a size in microns, $x \%_{\text {volume }}$ is inferior to this size). $D_{50}$ corresponds to the median particle size in volume.

Measured PSDs were described using different models. A Rosin-Rammler (RR) was used to model PSD obtained after disk mill comminution (Eq. 4). It is a typical 2-parameter model used to describe comminution process of minerals. Normal distributions were used to fit PSD with multiple modes obtained after sieving, recombination and ball milling (Eq. 5). Multi-peak fitting function from OriginPro 9 was used to model the distribution using normal distribution.

$$
Q(d)=1-\exp \left[-\left(\frac{d}{d_{1}}\right)^{m}\right],
$$

$$
q(d)=\frac{1}{\sigma \sqrt{2 \pi}} \exp \left[-\frac{\left(d-d_{m}\right)^{2}}{2 \sigma^{2}}\right] .
$$

With $d$ the size of particles, $q(d)$ the volume distribution, $Q(d)$ the cumulative volume distribution, $d_{\mathrm{m}}$ the median value of the distribution, $\sigma$ the standard deviation, $d_{1}$ the size for which $63.2 \%$ of the sample is inferior, and $m$ a coefficient dependant on the nature of the material.

The BET specific surface of samples was measured with a Micromeritics TriStar II PLUS. Samples were degassed under vacuum at $80{ }^{\circ} \mathrm{C}$ during $24 \mathrm{~h}$ prior to analysis. BETspecific surface was measured with nitrogen gas by a five pressures point method. Each sample was measured in duplicate.

The morphology of micronized particles was studied by image analysis. Four fractions were analyzed separately (0-40 $\mu \mathrm{m}, 40-100 \mu \mathrm{m}, 100-200 \mu \mathrm{m}$, and 200-315 $\mu \mathrm{m})$ to simplify sample preparation and to assess difference in morphology according to the size of the particles. Particles were dry dispersed on glass plates using sieves. Pictures of the particles were taken with a Leica optical microscope in transmission mode. Between 260 and 391 particles were analyzed for each fraction, for a total number of particles of 1414. ImageJ software was used to binaries pictures and to measure the area, the perimeter, and the elliptic and Feret dimension of each particle.

The morphology of particles was also observed with an ESEM (FEI Quanta 200 FEG). Particles were deposed on adhesive band to avoid movement, and coated with carbon. Pictures were taken in secondary and backscattered electron mode.

\section{Results and analysis}

\section{Material composition of the waste stream}

Only 42 models of electrical meters were identified in the sample. Some models represented a high number fraction of the sample in comparison with others. They were divided in three groups according to the outer casing material: metal, black/blue-painted plastic, and white plastic (Fig. 2). A link between the casing material and the age of the device was found: metal electric meter were the oldest, produced in the $50 \mathrm{~s}$, black plastic equipment were produced from the $60 \mathrm{~s}$ to the middle $90 \mathrm{~s}$, then they were replaced by white plastic materials. The black plastic EMs were found to represent the higher fraction of the sample, both in number and weight (Figs. 3, 4).

It can be seen that while white-plastic and metal-casing EMs represent almost the same fraction in number of the sample, the former represent a much lesser fraction in weight (Fig. 5). This can be explained by the different average weighted mass of EM in each type $(3.54 \pm 0.24 \mathrm{~kg}$ for metal casing EM, $2.95 \pm 0.17 \mathrm{~kg}$ for black plastic casing, $0.54 \pm 0.01 \mathrm{~kg}$ for white plastic casing). These different weights are related to the design and the specific gravity of the materials used in each EM. From an outside point of 
Fig. 3 Number and weight frequency distribution of electrical meter models in the sample

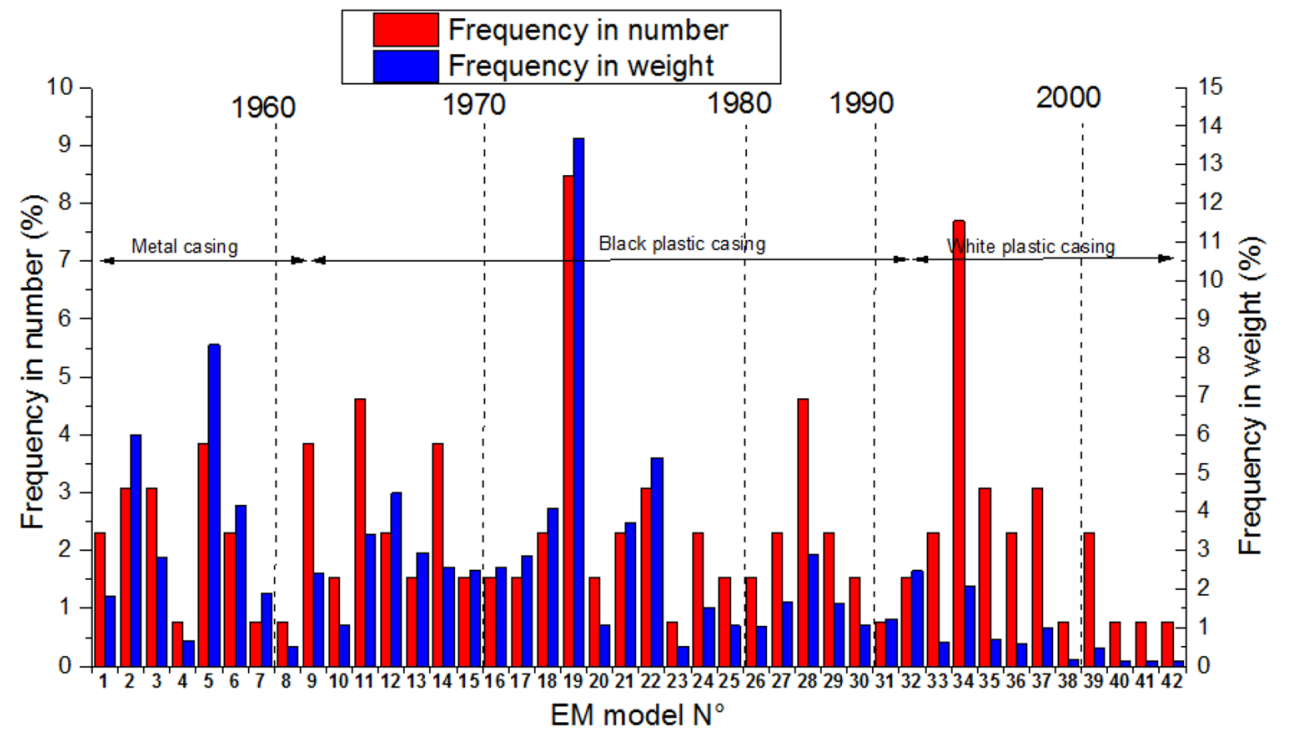

$24 \%$
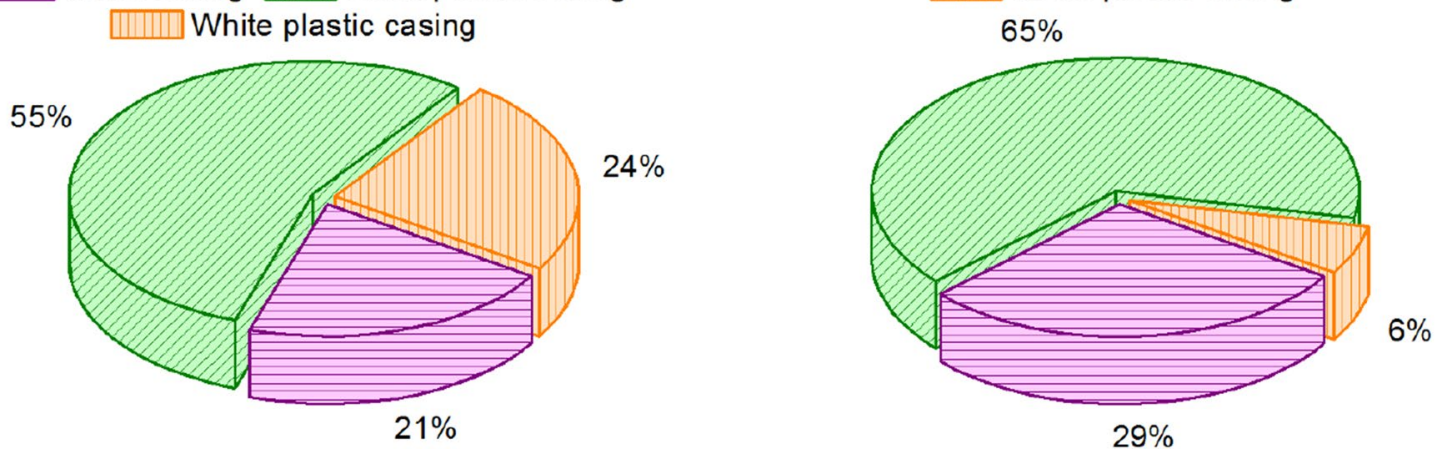

Fig. 4 Number (left) and weight (right) frequency distribution of type of electrical meter in the sample
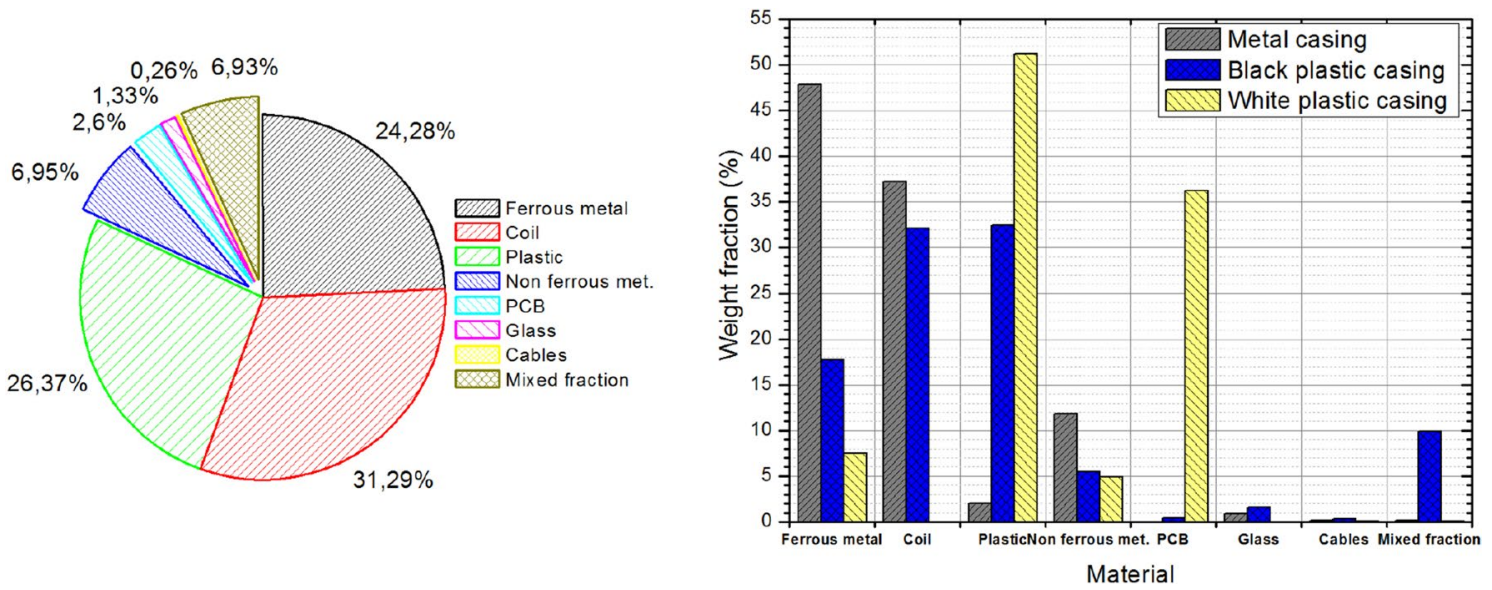

Fig. 5 Mass repartition of materials in the whole sample (left) and per EM type (right) 
view, metal and black plastic casing EMs are very similar in design, except for the material used for the casing.

EMs were dismantled to isolate materials and components. In terms of components and assembly, black plastic casing and metal casing EMs are very similar. They are electromechanical devices, with about the same type and number of parts and components. Only the materials used differ (especially for the casing). The same manual dismantlement scheme can be used for these two types of EMs. White plastics casing EM are different in terms of components, as they are electronic devices. They are mostly composed of PCB and casing. They are simpler in terms of assemblies.

Four basic types of materials were recovered (ferrous metal, non-ferrous metal, plastics and glass), and four types of components which could not be manually separated in individual materials (printed cardboards with LCD, coils, cables, and mixed materials) (Fig. 5). It appears that the sample is mostly composed of ferrous metal, plastics and coils. Single, isolated materials represent $59 \%_{\mathrm{w}}$ of the sample. This fraction is assumed to be directly mechanically recyclable. This might be true for metal and glass. The case of the plastic fraction will be discussed later. The assembly fraction (coils, PCB, cables), which represents $34 \%_{\mathrm{w}}$, might be valorized through sub-treatment (mechanical separation).

The plastic fraction of EMs might be the most troublesome in terms of recycling. Indeed, unlike metals, some plastics are not currently recycled (thermoset). Additionally, some additives traditionally used in plastic formulations, such as brominated flame retardant, are now regulated and excluded (or limited) in recycled plastics stream. Therefore, it is important to characterize plastics in a stream to assess its recyclability and to determine specific strategies to isolate desirable/undesirable materials.

142 samples of plastic materials have been extracted from the EMs and analyzed. Plastic materials represent an overall fraction of $26.4 \%$ in the sample. Depending on EM type, tremendous differences are observed, both in terms of overall plastic fraction and plastic types. These materials represent more than $50 \%$ of the mass of white plastic casing EM, while they are almost absent in metal casing EM.

Different types of plastics have been identified (Fig. 6). PMC was identified as the plastic composing the casing of black plastic EM. It actually constitutes $82 \%_{\mathrm{w}}$ of all plastic materials in this type of EM. White plastic casing EMs are mostly constituted of polycarbonate, and a small fraction of ABS-PC. No PMC was found in this type of EM. Some PMC was found in metal casing EM. However, it represents a very small mass fraction of these electrical meters. In the overall sample, PMC largely predominates, representing $71.3 \%$ of all plastics. That can be explained by the fact that black plastic casing EMs constitute most of the waste stream $\left(65 \%_{\mathrm{w}}\right)$, and their plastic fraction is mainly composed of PMC. The second most abundant plastic is polycarbonate, which comes from white plastic casing EMs. These two types constitute more than $85 \%$ of the analyzed plastics.

The EMs plastic stream is very different of the other plastics stream issued from various waste sources. For example, plastic in automobile are mostly composed of polyolefins (PP, PE) [55], while in EEE styrenic-based plastics dominate (PS, HIPS, ABS, ABS-PC, etc.) [56]. While PMC materials are sometimes used in these applications, they constitute only a very small fraction of all plastics. This is one of the reasons why they are not recovered and end up in landfill. No specific recovering strategies have been developed for such small fraction of material, for which no direct recycling strategy exist.

To devise a sorting strategy to recover materials with a high degree of purity, it seems interesting to first separate the stream in three family of EM. That can be done during collection or as a manual pre-sorting step. Indeed, the three types (metal casing, black plastic casing and white plastic casing EM) are very different in terms of material
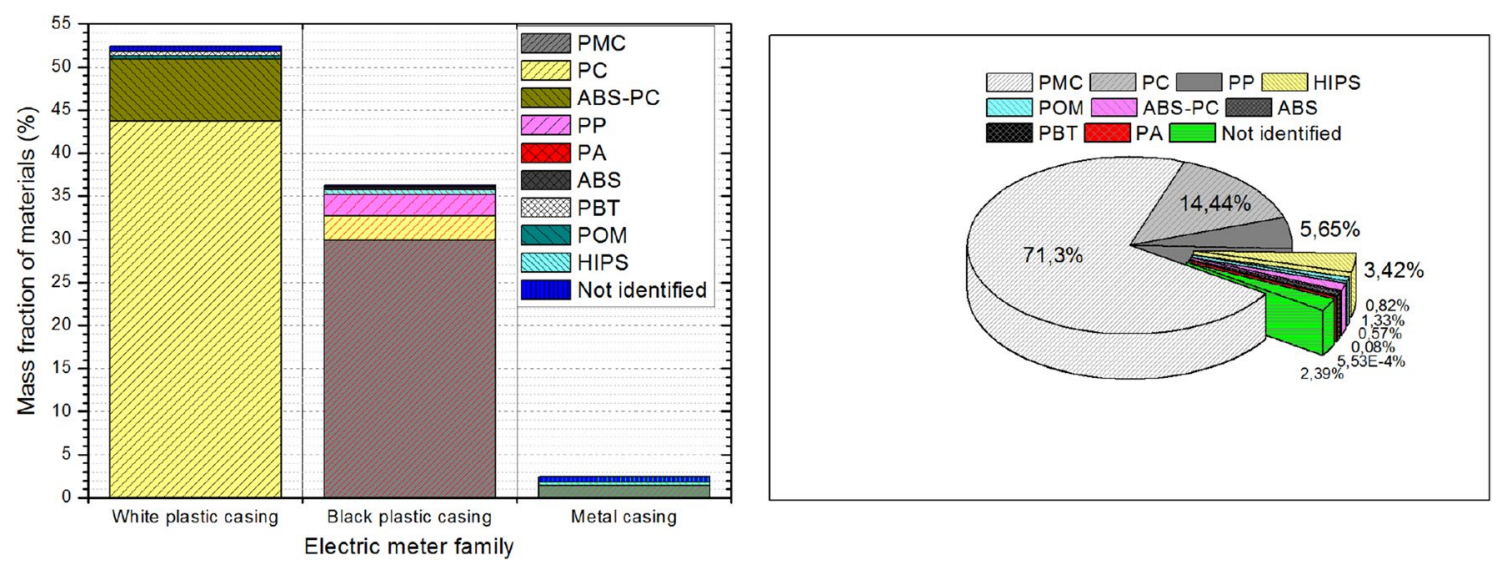

Fig. 6 Mass fraction of plastics in the different type of electrical meter (left) and composition of plastics in the overall sample (right) 
composition. The first one yields $97 \%$ of metal materials, which are easily sorted through conventional techniques (magnetic separation, eddy current separation, etc.).

A more significant fraction of plastic is found in black and white plastic casing EMs (32 and 51\%, respectively). The former is a PMC rich plastic stream (more than $80 \%$ ), which is a unique type of plastic stream. The latter is a PC/ABS-PC rich stream (more than 90\%), which can be compared with a WEEE or small household appliances type of stream in terms of plastic composition.

All collected PMC, PC and ABS-PC were submitted to a qualitative elemental analysis to assess the presence of regulated substances [57]. In PMC formulation, no substances such as mercury, cadmium, bromine, chromium, or lead was found. Thus, the all PMC streams were considered as unpolluted and reusable as a resource, without conflict with the legislation. Elements such as calcium and silicon have been found in most PMC, suggesting the presence of mineral fillers in formulations. In PC and ABS-PC, bromine with concentration between 5 and $10 \%$ was found in most formulation. Only two EMs contained PC without brominated flame retardant. From the analyzed sample, it was concluded that $79.6 \%$ of PC/ABS-PC in white plastic casing EM contained brominated flame retardant.

In the overall sample, plastics represent $26.4 \%_{\mathrm{w}}$ of all materials. It appeared that they are mostly composed of two types of polymers, PMC and PC/ABS-PC $(85 \%$ of all plastics, $22.4 \%_{\mathrm{w}}$ of all materials and assemblies). While for the former, no direct industrial valorization exists, the latter is highly polluted with a regulated substance (brominated flame retardant), which hinder its possibility of recycling. This fraction is therefore hardy recyclable, and seriously limits the overall recyclable fraction of the waste stream. This might be a problem in regard with the regulation. For brominated plastics, some feedstock recycling solution through pyrolysis or hydrothermal treatment have been proposed [58]. In this work, a process to valorize the thermoset fraction is proposed and is developed in the next section.

\section{Characterization of recovered PMC}

After the PMC parts were identified and isolated, they were characterized by different means to better understand their composition. Indeed, it is known from the literature that PMC are compounds, which means that they are phenolic resin reinforced with various fillers and additives [59]. This step is important to specify sub-sorting step of the PMC stream. It can be necessary if regulated substances are present in some formulation for example, or if different types of compositions exist in the pool which could valorized in different ways (i.e. materials recycling for glass fiber reinforced PMC, thermal valorization for organically filled PMC, etc.).
A reduced number of PMC samples have been fully characterized. They have been only extracted from black plastic casing EM. Depending on the type of analysis, between 4 and 9 PMC samples extracted from single EMs were studied. Indeed, it was shown that some EMs were far more abundant than other in the waste stream. Thus, PMC formulations from these EMs represent a higher fraction of the overall PMC pool. Knowing the mass fraction $F_{\text {mass }}($ EMk) of each EM in the stream and the mass fraction of PMC in each $\mathrm{EM}$, it was possible to calculate the relative mass repartition of PMC issued from each EM (PMC1, PMC2,.., PMCn) (Fig. 7).

By choosing PMC part from four specifics EMs, the analysis covers more than $65 \%$ w of all formulations. These 4 PMC samples (no 1-4) constitute the core sample, and were subjected to all types of analysis. Depending on the type of analysis, additional PMC samples were also analyzed to increase the representativeness and achieve stronger conclusion. Indeed, by studying the 8 most abundant PMC samples, the representativeness increases to $95 \%$ w.

First, a more quantitative elemental analysis was carried out by EDX to determine the type of mineral fillers present in the formulations. A very low amount of mineral elements was found in all the formulation, generally below $4 \%$ (Fig. 8). The other elements are carbon, oxygen and nitrogen, which correspond to the organic matrix.

Calcium and silicon are found in all formulations. Some elements such as magnesium are also often found. Fillers observed on fractured surface have size ranging from $200 \mu \mathrm{m}$ to few microns (Picture 1). Elemental analysis of individual filler particles was performed to attribute identified atomic elements to specific mineral fillers composition. It showed that most formulation included calcium oxide and silica (Table 1).

Calcium oxide is often used as a catalyst for hardening in PMC formulation, while small amount of silica can be used to modify rheological properties. In some formulations,

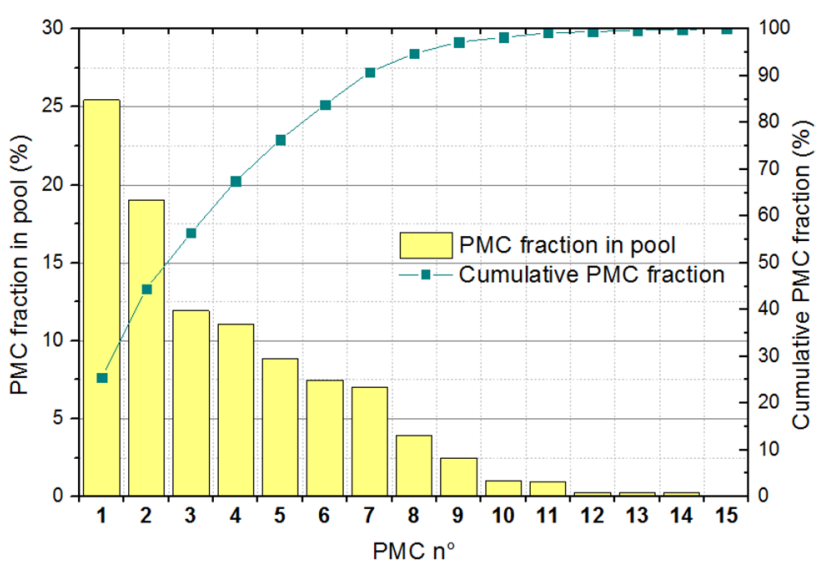

Fig. 7 Mass fraction of each PMC part in the overall PMC pool 


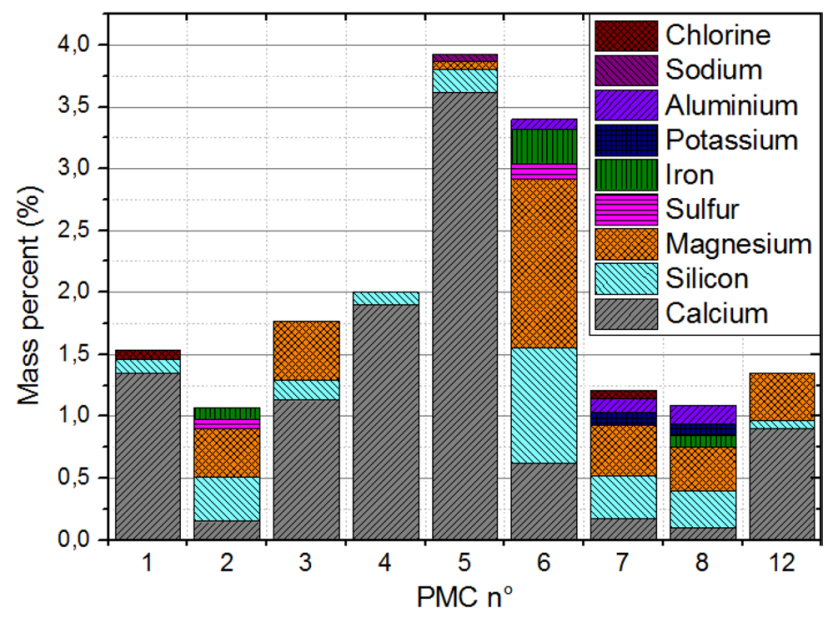

Fig. 8 Elemental analysis of the PMC formulation by EDX

magnesium could not be identified in mineral fillers, suggesting its presence in a molecular form. That might be in a form of magnesium stearate, a commonly used lubricant for this kind of material. Small amount of nitrogen has also been identified. That suggests that the phenolic resin used in the formulation of this PMC is a Novolac type, which is often hardened with a nitrogen-containing hardener, the HMTA. This could explain the presence of chlorine in some samples. Indeed, hydrochloric acid is sometime used as a catalyst in the condensation process of Novolac prepolymer [60].

Second, elongated organic particles can be seen in SEM pictures of all formulations. They can be identified as wood particles. To assess more precisely the amount of wood flour in the formulations, polished surfaces were observed with an optical microscope (Leica) (Picture 2).

It can be seen that wood flour represents a high fraction of the material. Surface fraction measured by image analysis ranges from 44 to $47 \%$. Unfortunately, it is not straight forward to calculate volume or mass fraction from surface fraction for this type of irregularly shaped particles.
Another way to determine the type of fillers and its fraction in PMC formulation is to measure the density (Fig. 9). Measured densities fall between 1.31 and $1.39 \mathrm{~kg} / \mathrm{L}$. This is the typical density range of wood flour filled PMC.

Assuming the density of cured phenolic resin $(1.25 \mathrm{~kg} / \mathrm{L}$, $3.5 \%$ of mineral), and the density of wood flour $(1.47 \mathrm{~kg} / \mathrm{L}$, spruce WF), it is possible to calculate the theoretical mass fraction of wood flour in the PMC formulations. Values ranging from 25 to $65 \%$ are obtained.

Finally, mechanical properties (tensile and impact) of PMC formulations were measured (Error! Reference source not found Fig. 10). An average flexural modulus of $7.8 \pm 0.7$ $\mathrm{GPa}$ and a flexural strength of $86 \pm 7 \mathrm{MPa}$ were obtained. The material showed a very brittle behavior, with a deformation at break of $1.1 \%$, which is expected for this type of thermoset material. Interestingly, all values are quite close, which is surprising when considering the age of the samples (roughly between 25 and 50 years old). They are also very close to value find in the literature for wood floor filled PMC. That demonstrates the good durability of this material.

An average impact strength of $4.6 \pm 0.5 \mathrm{~kJ} / \mathrm{m}^{2}$ was measured. This value is very low in comparison with other plastic materials. Again, measured values for different PMC are

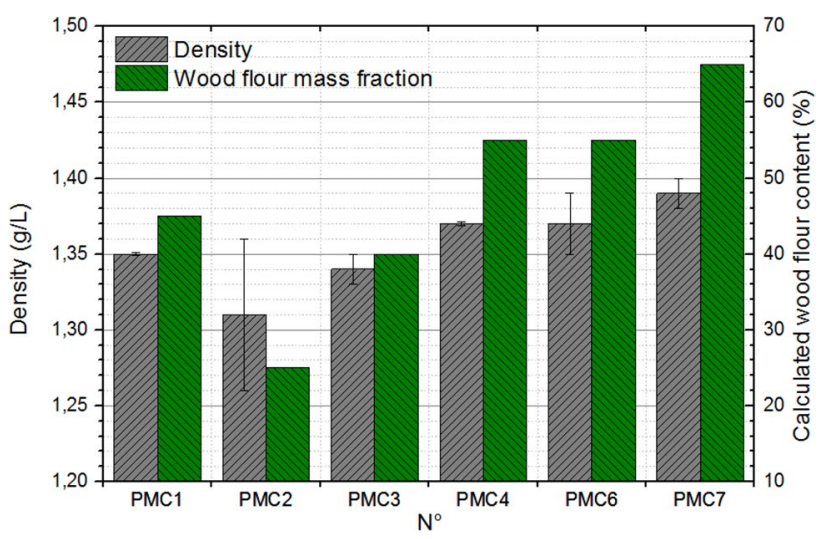

Fig. 9 Measured densities of PMC and calculated wood flour content

Table 1 Identification of fillers present in PMC formulation (9 PMC samples)

\begin{tabular}{|c|c|c|c|c|}
\hline Mineral filler & Chemical formula & $\begin{array}{l}\text { Fraction of total PMC pool con- } \\
\text { taining the filler }(\%)\end{array}$ & $\begin{array}{l}\text { Typical size of filler } \\
(\mu \mathrm{m})\end{array}$ & $\begin{array}{l}\text { Maximum } \\
\text { observed size } \\
(\mu \mathrm{m})\end{array}$ \\
\hline Calcium carbonate/oxide & $\mathrm{CaCO}_{3} / \mathrm{CaO}$ & $70.6 \%$ & $1-30$ & 276 \\
\hline Silica & $\mathrm{SiO}_{2}$ & $58.7 \%$ & $4-37$ & 237 \\
\hline Magnesium carbonate/oxide & $\mathrm{MgCO}_{3} / \mathrm{MgO}$ & $15.6 \%$ & $13-45$ & \\
\hline Steatites & $\mathrm{Mg}_{3} \mathrm{Si}_{4} \mathrm{O}_{10}(\mathrm{OH})_{2}$ & $13.1 \%$ & $8-37$ & 150 \\
\hline Iron & $\mathrm{Fe}$ & $9 \%$ & $12-14$ & \\
\hline Aluminosilicate & $\mathrm{KM}\left(\mathrm{AlSi}_{3} \mathrm{O}_{10}\right)(\mathrm{OH})_{2}{ }^{*}$ & $7.9 \%$ & $4-39$ & \\
\hline Glass fiber & & $3.3 \%$ & $8-115$ & \\
\hline
\end{tabular}



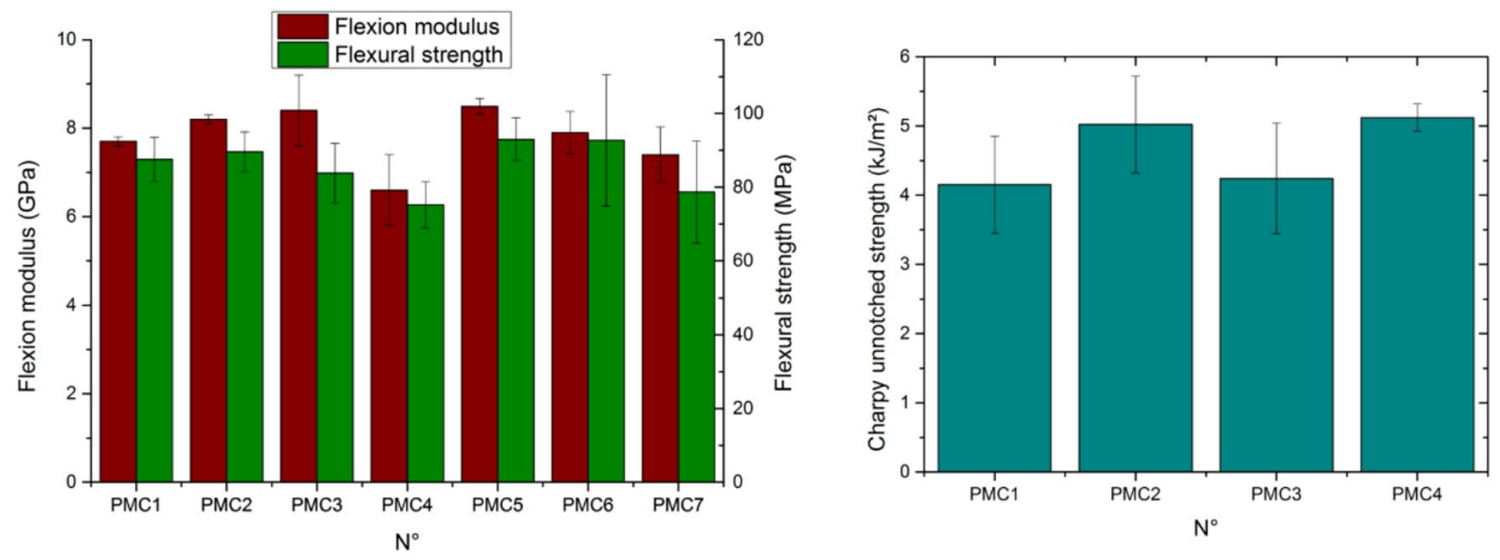

Fig. 10 Flexural modulus and strength (left) and Charpy impact strength (right) of PMC

quite close, and comparable to value found in literature for wood flour filled PMC.

$67-95 \%_{\text {weight }}$ of the PMC formulation from the waste pool was characterized by different means. All results are consistent and show that only one type of PMC was used to produce electrical meter casing over a period of 40 years. It is a Novolac phenolic resin-based material, with less than $5 \%$ of mineral filler and about $50 \%$ of wood flour.

On a limited number of casing, a "P21" stamp was present. This corresponds to PMC formulation denomination in the CEMP11 norm, which was used in France until 1980. It designates a wood flour filled formulation. In more recent norm, such as ISO 800 or ISO 14526-3, it corresponds to PF2A1 and WD40MD5, respectively.

\section{Characterization of comminuted PMC}

To be used as filler, the PMC has to be comminuted to the appropriate size. Fillers typically used in thermoplastic materials can be found in a wide range of size, from tens of microns to hundreds of microns. While it is generally admitted that better mechanical performances in composites materials are obtained with the smallest fillers, the limitation in terms of minimum achievable size is generally dictated by the cost of the comminution process (which rises with the finesse of obtained product). The goal of this study is to determine the achievable particles size through different processes and determine related yields.

\section{Coarse grinding step}

The effect of the size of the grid on crushed products PSD was studied in the first step of the comminution scheme. The maximum size of the grinded particles is always 1 or $2 \mathrm{~mm}$ below the size of the grid used (Fig. 11). This might

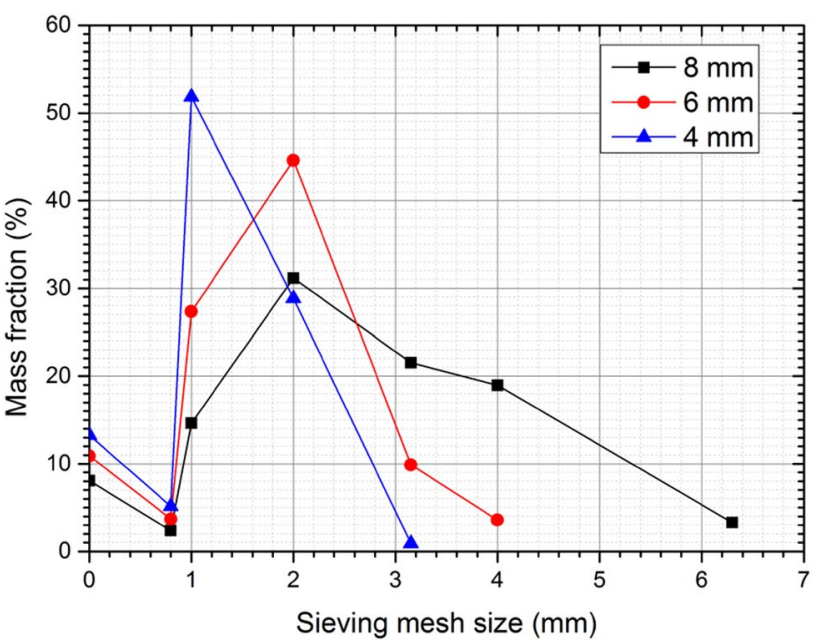

Fig. 11 Mass PSD of PMC crushed with a knife mill with 3 sizes of grid, measured by sieving (1500 rpm)

be due to the low impact strength of the material, which fractures easily under high-speed impact.

For both 6 and $8 \mathrm{~mm}$ grid, most particles are between 2 and $3.15 \mathrm{~mm}$ in size. A broader distribution is obtained with the $8 \mathrm{~mm}$ grid. Switching to $4 \mathrm{~mm}$ grid allows a reduction of the size of the crushed product: more than $50 \%$ of the particles have a size between 1 and $2 \mathrm{~mm}$. It also leads to increase in residency time in the crushing chamber and difficulty in the grinding process. It was not possible to use a smaller grid such as $2 \mathrm{~mm}$. Indeed, the pre-crushed PMC pieces have length and width up to $5 \mathrm{~cm}$, while their thickness ranges from 2 to $4 \mathrm{~mm}$. To be comminuted with a $2 \mathrm{~mm}$ grid, most pieces have to be reduced in thickness, which leads to very long residency time and heating of the material. The same phenomenon hindered the comminution with the $4 \mathrm{~mm}$ grid. 


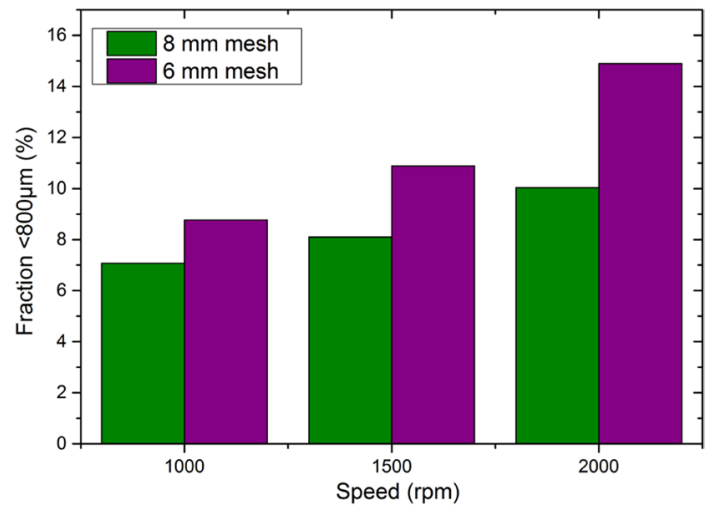

Fig. 12 Fine fraction $(<800 \mu \mathrm{m})$ production in a knife mill as a function of knife speed and grid size

The knife rotation speed does not change much the particles size distribution. A shift of the cumulated PSD to the left of the smallest size fractions can be noticed.

This corresponds to a higher production of fine particles. It is particularly obvious in the finest fraction $(<800 \mu \mathrm{m})$ Fig. 12. An increase of fine particles is observed at higher rotation speed and lower grid size. Up to $15 \%$ of fine particles are produced with a $6 \mathrm{~mm}$ grid and a $2000 \mathrm{rpm}$ knife rotation speed. The effect of knife rotation speed might be explained by the higher impact energy at high speed, which leads to more fractures, and the increased number of impact during the residency time. It also leads to more heating in the chamber.

During this step, material losses ranging from 1.1 to 5.7\% were recorded. They could not be correlated with grinding parameters. They correspond mostly to particles stuck in the grinding chamber.

For the next step, a coarse grinding with a $6 \mathrm{~mm}$ grid and a knife rotation speed of $1500 \mathrm{rpm}$ was selected, as it provides a narrow and relatively small particle size distribution ( $72 \%$ of particles between 1 and $3.15 \mathrm{~mm}$ ) and mild condition of crushing. A $1.1 \%$ material loss was considered for this step.

\section{Micronization step}

Particle sizes of hundreds of microns were obtained through the disk mills micronization process (Fig. 13 Error! Reference source not found). A proportional decrease of the PSD is observed with decreasing disk spacing. The $\mathrm{d}_{90}$ of PSD is always about $1 \mathrm{~mm}$ below the disk spacing, while the maximum measured particles size in each sample is the same as the disk spacing.

Median particle sizes from 272 to $494 \mu \mathrm{m}$ were obtained through this process. The cumulated PSD can be fitted with a Rosin-Rammler model (Eq. 4). $m$ parameters ranging from 1.29 to 1.37 were obtained. The distributions are very broad.

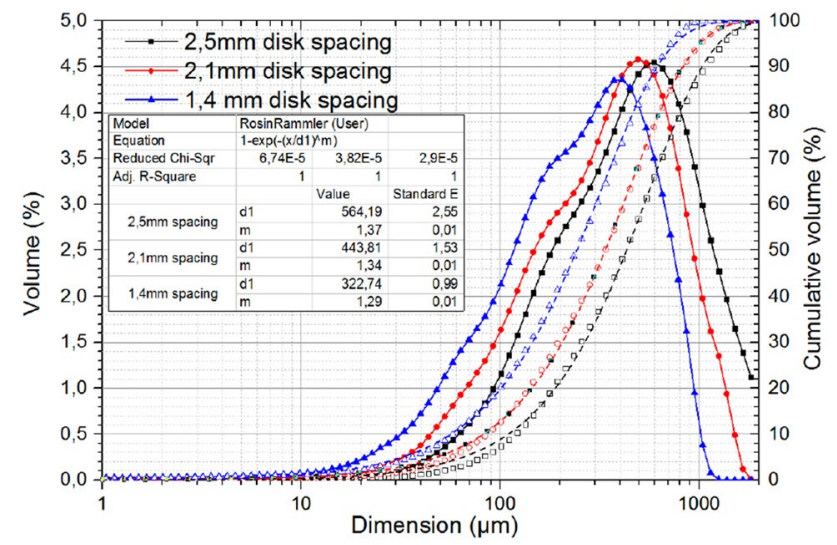

Fig. 13 Laser PSD of micronized PMC (disk mill) for different disk spacing. Hollow dots represent measured cumulative PSD, dashed lines correspond to RR fit

Even for the product micronized with the smallest disk spacing $(1.4 \mathrm{~mm})$, a $d_{90}$ of $685 \mu \mathrm{m}$ is obtained. This product can hardly be used as filler as it is too big. Additional steps are required to prepare the filler. It can also be noticed that PSDs are multimodals. At least two modes exist in all PSDs (one at $180 \mu \mathrm{m}$, present in all PSDs, and one corresponding to the highest peak). In the next step of the scheme, the smallest PSD obtained through this process (1.4 $\mathrm{mm}$ spacing) was used. With the process setting, an average material loss of $4.7 \%$ was recorded.

The easiest way to reduce the size of the distributions is a top cut, which consists in sieving the powder to eliminate particles bigger than the sieve mesh size. Four top cuts were performed on the micronized products, with 400, 200, 100 and $40 \mu \mathrm{m}$ sieves (Fig. 14) Error! Reference source not found.

Powders with median size diameters between 188 and $24 \mu \mathrm{m}$ are obtained through this step. A yield of $84 \%$ is obtained with a $400 \mu \mathrm{m}$ cut, $56 \%$ with a $200 \mu \mathrm{m}$ cut, $33 \%$ with a $100 \mu \mathrm{m}$ cut and $17 \%$ with a $40 \mu \mathrm{m}$ cut. Because of the process, asymmetric PSDs are obtained. Multimodal distributions are again observed. It is possible to fit the distribution with multiple Gaussian peaks (Table 2). A finite amount of shared peak allows modeling all the PSDs. Five Gaussian distributions were used, with peak centers ranging from 331 to $9.7 \mu \mathrm{m}$. The PMC PSD can be fitted with 2 or 3 of these distributions.

This reflects the polymodality of the PSD obtained through the disk mill comminution process. While the presence of multiple modes can be seen on the original PSD, it becomes even more obvious and quantifiable on top cut PSD.

Another method to assess the size and surface feature of powder is to measure their specific surface area, i.e. the total surface developed by a given mass of material. For these 


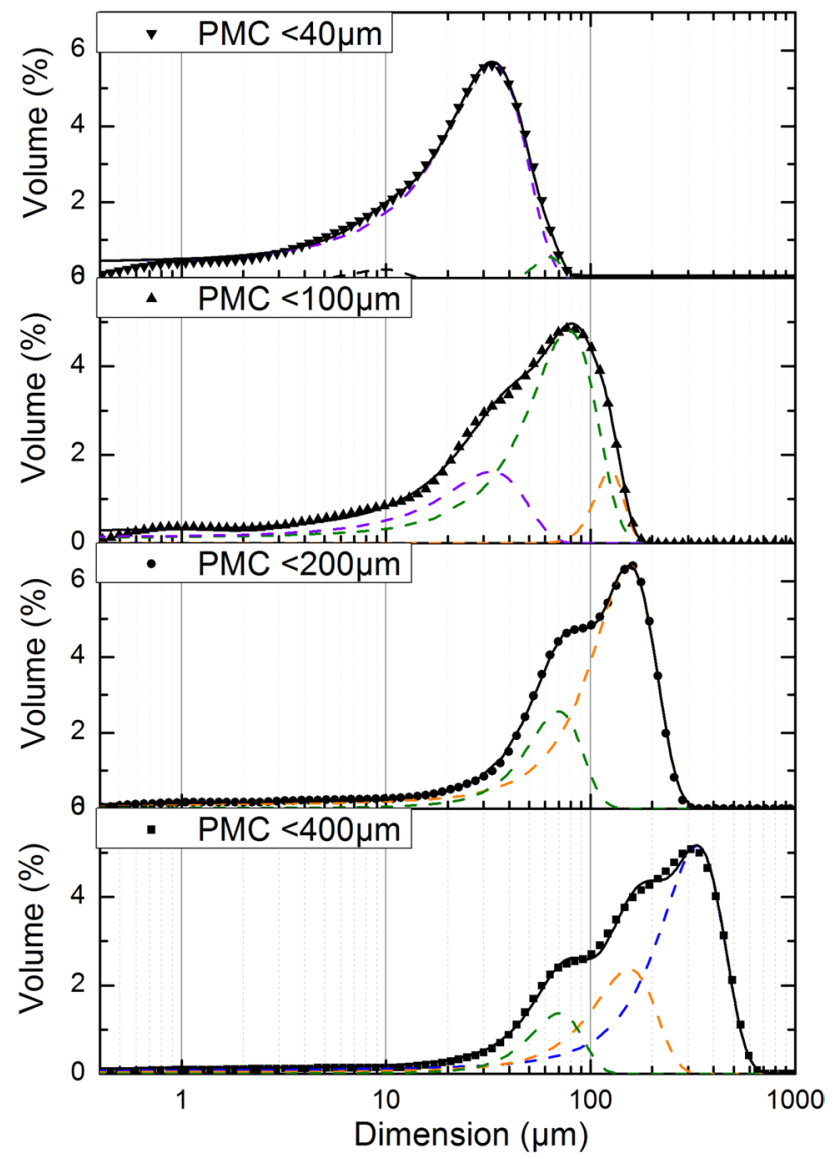

Fig. 14 Particles size distribution obtained through sieving (400, 200, 100 and $40 \mu \mathrm{m})$ measured by laser diffraction. Black lines are multiple peak fits, colored lines are single Gaussian peaks

four PSDs, an increase in BET surface area is measured with decreasing sieving mesh size (Fig. 15).

It is related to the statistical decrease of the size of the powder. Indeed, smaller particles develop a higher surface in comparison with bigger one. The measured BET surface is much higher than the theoretical surface area developed by sphere with equivalent diameter as measured by LS. These surface areas are also rather high in comparison with typical mineral fillers when considering the size of the particles. For example, for a Piketty calcium carbonate with a $d_{50}$ of $6 \mu \mathrm{m}$ (laser PSD), a BET surface area of $0.75 \pm 0.02 \mathrm{~m}^{2} / \mathrm{g}$ was measured. While this $\mathrm{CaCO}_{3}$ has a similar BET surface as the PMC top cut at $200 \mu \mathrm{m}$, its median size diameter is about 17 times lower. That suggests that PMC particles have not a flat and homogeneous surface, as pores and surface features can increase the surface area. This might be also due to the wood fraction in the PMC, which has a porous structure.

While laser diffraction PSD and BET surface measurements gave information about the size and surface state of comminuted PMC particles, the morphology and shape of particles are not known. These parameters are useful to interpret data from the two former characterization techniques. To study the morphology of comminuted products, five fractions of micronized particles were studied by image analysis. Pictures of dispersed particles taken with an optical microscope were analyzed. Feret minimum and maximum diameter of particles was measured for each fraction (Fig. 16).

Maximum and minimum Ferret diameter for each fraction are shifted, which shows that particles are not spherical but elongated. The minimum Ferret diameter falls in the range of the sieving mesh size (except for the 315-400 $\mu \mathrm{m}$ fraction). This is expected as it corresponds to the minimum size of the particle, which is able to pass through the mesh. A elongation factor (EF) superior to one is found in all fractions (Fig. 17). As the size of the particles decreases, the elongation factor increases. While these particles cannot be considered strictly spherical or block shaped, they are not elongated enough to be considered as circular $(\mathrm{EF}=2$ to - 10) or fiber like. From these two-dimensional measurements, it is not possible to determine if the particles are flake like (i.e. with a small thickness in comparison with length and width).

The reason for this shape might be process related, or linked to the microstructure of PMC, which contain elongated wood particles with size ranging from tens of microns to a few hundred microns. The size of comminuted PMC particles is within or below the size range of wood particles inside it. During the comminution, the fracturation of the material might be helped by the presence of these fillers and the defects they constitute, leading to a particle morphology reflecting the original microstructure.

Morphology of micronized particles was also observed with a scanning electron microscope. The particle shape appears to be relatively random, from almost spherical to more elongated shape (Picture 3 ). The most elongated
Table 2 Peak center and area fraction of Gaussian distribution used to model top cut PSD

\begin{tabular}{|c|c|c|c|c|c|c|c|}
\hline \multicolumn{2}{|c|}{ PMC $<\mathbf{4 0 0} \boldsymbol{\mu m}$} & \multicolumn{2}{c|}{ PMC $<\mathbf{2 0 0} \boldsymbol{\mu m}$} & \multicolumn{2}{c|}{ PMC $<100 \mu \mathrm{m}$} & \multicolumn{2}{c|}{ PMC <40 $\boldsymbol{\mu m}$} \\
\hline Peak $(\mu \mathrm{m})$ & Area $(\%)$ & Peak $(\mu \mathrm{m})$ & Area $(\%)$ & Peak $(\mu \mathrm{m})$ & Area $(\%)$ & Peak $(\mu \mathrm{m})$ & Area $(\%)$ \\
\hline 331 & 79.5 & & & & & & \\
\hline 155 & 16.8 & 154 & 86.4 & 125 & 16.9 & & \\
\hline 70 & 3.7 & 70 & 13.6 & 78 & 71 & 63 & 6.9 \\
\hline & & & & 33 & 12.1 & 33 & 92.1 \\
\hline & & & & & & 9.7 & 1 \\
\hline
\end{tabular}




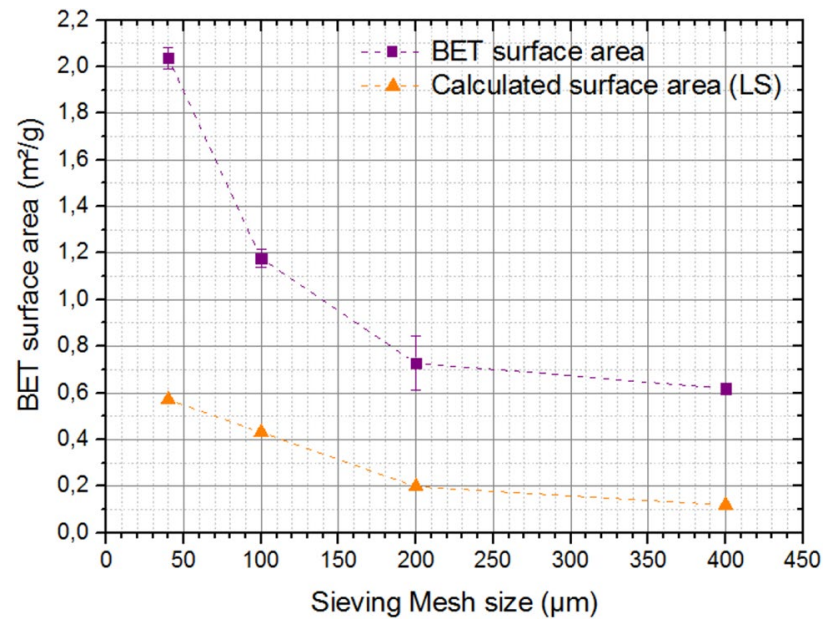

Fig. 15 BET surface area of sieved powder as a function of sieving mesh size (Square: measured; Triangle: equivalent spherical surface calculated from laser scattering PSD)

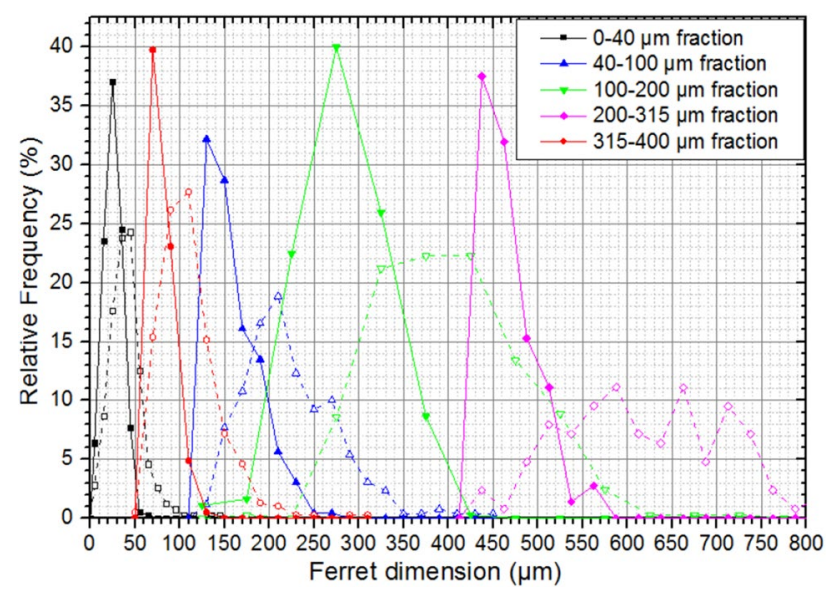

Fig. 16 Minimum (solid line, full dots) and maximum (dashed line, hollow dots) ferret diameter of fives fraction of particles measured by image analysis

particles look like wood floor. Some of them appear to be fully decapsulated from the resin matrix, or partially covered with the matrix. On some particles, wood fibers stick out of the surface. Mineral particles can also be pointed out on the surface of comminuted particles. As showed by BET measurement, the surface of particles appears rough and highly textured. For comparison, Piketty calcium carbonate has a smooth and regular surface.

The elongated shape of particles has a direct impact on size measured by laser diffraction (LS). Indeed, this technique assumes the sphericity of the particles in the calculation of its size from its diffraction pattern. One size is calculated for every particles (equivalent diameter), while they can have several characteristics dimension related to

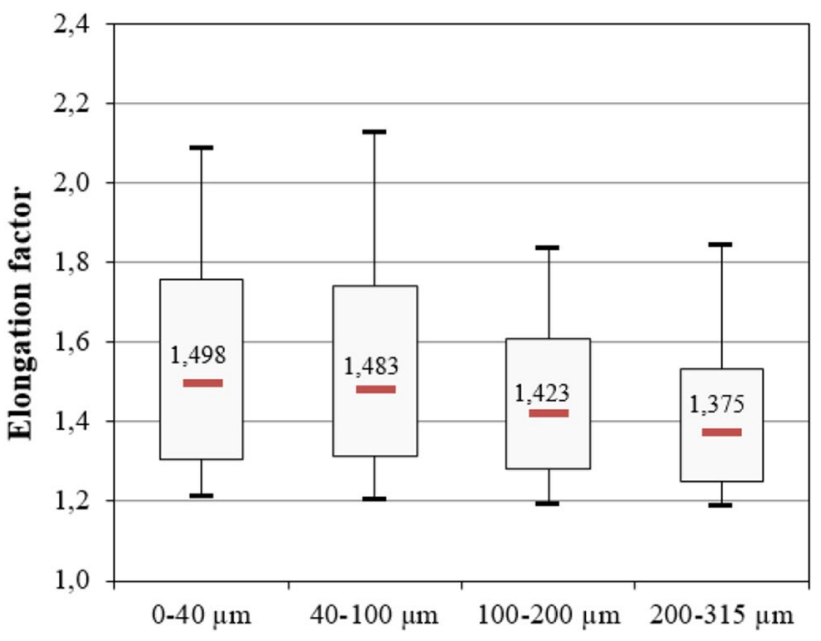

Fig. 17 Elongation factor of different PMC size fractions measured by image analysis (central line: median value, upper/lower corner of the box : $d_{75} / d_{25}$, upper/lower bounds : $d_{90} / d_{10}$ )

their shape (two dimensions for a rode, three for flakes, etc.). Elongation of particles generally leads to broadening of the PSD measured by LS [61]. For large aspect ratio (>10), two or three modes corresponding the different dimensions of the particles can appear in the PSD. Interestingly, in the case of PMC powder, the observed modes are all separated in size by a factor of about 2 . While it could be related to the characteristic size (length, width, thickness) of elongated particles, it is unlikely the case, as the volume fraction of each peaks is very different. From these considerations, it can be stated that the LS measurement method of size leads to a slight overestimation of the broadness of the distribution of the comminuted PMC, as well as a shift of the distribution to the larger size. This is verified by the measurement of particle size distribution by sieving. For example, while LS measures 20, 42 and $73 \%$ of the powder volume fraction inferior to 100, 200 and $400 \mu \mathrm{m}$, respectively, the mass fraction measured by sieving is 33,56 and $84 \%$. The apparent PSD measured by sieving, which corresponds to the two smaller dimensions of particles (thickness and width), is indeed smaller than the one measured by LS.

Through this top cut process, the smallest PSD obtained had a median diameter of $24 \mu \mathrm{m}$ and a very low yield (17\%). Another approach was undertaken to try to obtain a smaller PSD with a higher yield, through a third comminution step. The fraction above $200 \mu \mathrm{m}$ was comminuted using a ball mill during a different amount of time to assess the minimum achievable PSD. Two sets of balls were used depending on the size of the product to be comminuted.

After $13 \mathrm{~h}$ of comminution with the first set of balls, the median diameter is almost divided by 8 (Fig. 18). Initially, this distribution was the retained fraction in a $200 \mu \mathrm{m}$ sieve, meaning all particles were bigger than $200 \mu \mathrm{m}$. After this 


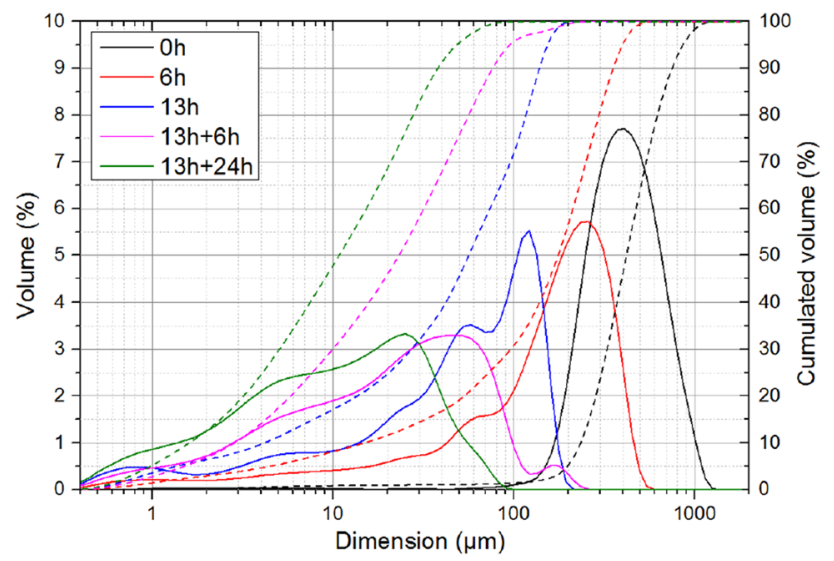

Fig. 18 Particle size distribution measured by laser diffraction of PMC comminuted in a ball mill during different times (First ball set milling time + second ball set milling time)

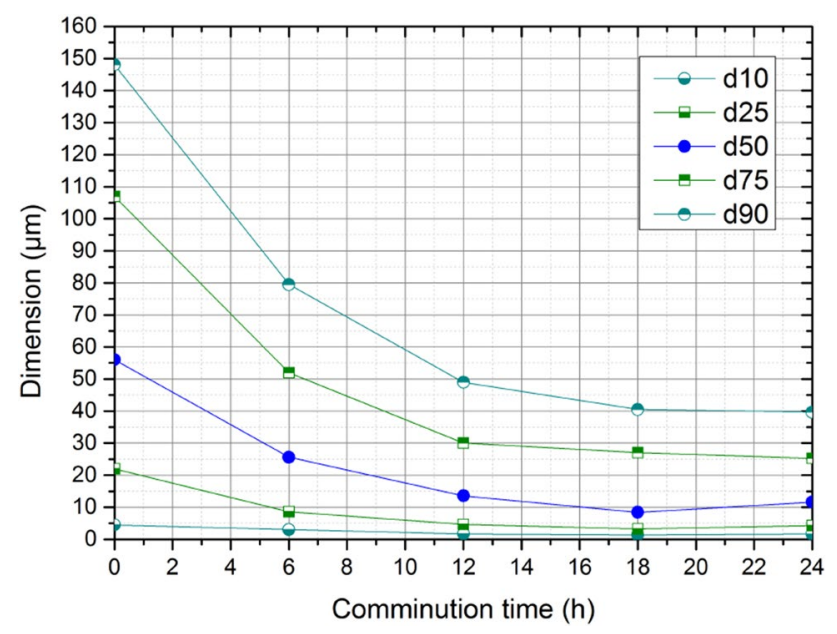

Fig. 19 Particle size distribution measured by laser diffraction of PMC comminuted in a ball mill during different times (second ball set milling time)

step, they all pass the $200 \mu \mathrm{m}$ sieve. While the initial particle size distribution was monomodal, the distribution changes during the comminution and multiple modes appear. Further comminution is achieved with the second set of balls (Fig. 19). A minimum size was achieved between 12 and $18 \mathrm{~h}$ of comminution, with a median size diameter between 13 and $8 \mu \mathrm{m}$. Again, obtained PSDs are multimodals (after $24 \mathrm{~h}$, two mains modes at 24 and $6 \mu \mathrm{m}$ ). While the initial distribution appears symmetrical, asymmetry develops during the comminution, with most of the distribution smaller than the main mode (right-side asymmetry).

This evolution of PSD suggests a comminution process mainly dictated by a mode of fracture of the particles, with creation of fractured sub-particles with a wide-size distribution. Some attrition also occurs, as suggested by the appearance of a small fraction of particles in the microns size range at the beginning of the comminution. This process allowed a significant size reduction with no material loss. However, it was not possible to control the exact distribution obtained, as asymmetry and polymodality developed during the comminution process.

\section{Conclusion}

In this work, a waste stream composed of electric meter was studied in terms of design and material composition. A particular approach was adopted, consisting in a macro study of an EM sample to determine its general features (yielding design generality, type/sub-type of equipments, existing models and mass/number repartition in the sample), an individual appliances dismantlement and analysis (yielding specific design of appliances, variance in design, dismantlement scheme, material composition, variance in composition), and calculation of material composition of the sample through extrapolation of dismantlement and sample study data.

Amongst the 42 models of EM present in the sample, 3 main type of EMs were identified according to their casing material. The most abundant type was the black/blue-painted plastic casing. In terms of design, this type was similar to EM with metal casing. They are both electromechanical appliances, with similar components. The third type was an electronic appliance with white plastic casing. The material composition of these three types of EM was very different. Metal-casing EMs were mostly composed of metal and coils (85\%), black plastic casing had a more balanced composition with about $30 \%$ of plastic, $30 \%$ of coil and $23 \%$ and metal, and white plastic casing were mostly composed of PCB and plastic. Within each type, the material composition variance between models was low.

These three types of EMs reflected an evolution in design over the second half of the twentieth century. The oldest type, the metal-casing EM, which was produced until the late 1950 s, was mostly metallic. In the 1960, plastic materials were democratized in the fabrication of these appliances (black plastic casing). The overall design did not change much. In the 1990, electronic systems were introduced, with a change in plastic material used (PC/ABS-PC).

The statistics of the EM sample (models, frequency of models in sample, type repartition, etc.) were compared to the statistics of the overall EM pool obtained through a survey. The models analyzed in this study were the most abundant in the pool and represented more than $80 \%_{w}$ of the whole stream. However, the relative fraction of each EM model and type in the sample did not fully matched with the repartition of the overall stream. Electronic EMs were under represented in the sample, and metal-casing EMs were over 
represented. This led to some error in the material composition balance. For the most abundant material fraction (ferrous metal, coil, plastics), the relative error induced was of about $10 \%$. For smaller fraction, such as PCB, the relative error exceeded $100 \%$.

In terms of recyclability, the peculiarity of this waste stream lies in its plastics fraction $(28 \% \mathrm{w}$ of the stream). Its main type of plastic is a phenolic molding compounds, a thermoset material. This material cannot be directly mechanically recycled because of its chemical structure. The second most common plastics in the stream are PC and ABS-PC. Elemental analysis showed that most of these two polymers were ignifugated with brominated flame retardant. These substances are regulated under RoHS (Restriction of Hazardous Substances, 2002/95/CE), therefore, they hinders possibilities of recycling for these materials. A significant part of this waste stream is troublesome in terms of recycling. To allow a higher part of the stream to be recycled, a solution to valorize PMC was proposed, consisting in using it as functional filler in a thermoplastic matrix.

The first step to transform PMC waste into functional filler was investigated in this work. It consists in comminuting the material to the appropriate size, which is typically below $50 \mu \mathrm{m}$. Different schemes were used to reduce the size to particle from tens to hundreds of microns. A twostep comminution scheme using a knife mill and a disk mill did not allowed sufficient size reduction, as the minimum median diameter obtained was superior to $250 \mu \mathrm{m}$. A third step, either a selection or another comminution with a ball mill, allowed to decrease significantly the size of the particle.

Similar or higher values than talc-filled PP can be obtained, showing that PMC can be used as semi-reinforcing filler [62]. This work, published in 2017 by Bernardeau et al., showed that this thermoset material can be recycled as functional filler in a thermoplastic matrix, improving its mechanical properties in a similar way as conventional semireinforcing filler such as talc. This recycling process allows substitution thus saving of natural resources, while limiting the environmental impact of landfilling.

Acknowledgements The authors wish to thank the companies APR2 and ENEDIS for their financial support to this work

\section{References}

1. Ministère de l'environnement de l'énergie et de la mer (2014) Filières de responsabilité élargie du producteur (REP)," Developpement-durable.gouv, 2014. [Online]. http://www.developpement-durable.gouv.fr/Vehicules-Hors-d-Usage-VHU,12759.html [Accessed: 09-Dec-2016]

2. DIRECTIVE 2002/96/CE DU PARLEMENT EUROPÉEN ET DU CONSEIL (2003) du 27 janvier relative aux déchets d'équipements électriques et électroniques (DEEE) J Off l'Union Eur:24-38

3. Marques AC, Cabrera Marrero J-M, C de Fraga Malfatti (2013) A review of the recycling of non-metallic fractions of printed circuit boards. Springerplus, vol 2, p 521

4. Ademe (2016) Rapport annuel du registre des déchets d'equipements électriques et électroniques

5. Hischier R, Wäger P, Gauglhofer J (2005) Does WEEE recycling make sense from an environmental perspective? Environ Impact Assess Rev 25(5):525-539

6. Mar-Ortiz J, González-Velarde JL, Adenso-Díaz B (2011) Designing routes for WEEE collection: the vehicle routing problem with split loads and date windows. J Heuristics 19(2):103-127

7. Zoeteman BCJ, Krikke HR, Venselaar J (2009) Handling WEEE waste flows: on the effectiveness of producer responsibility in a globalizing world. Int J Adv Manuf Technol 47(5-8):415-436

8. Veenstra A, Wang C, Fan W, Ru Y (2009) An analysis of E-waste flows in China. Int J Adv Manuf Technol 47(5-8):449-459

9. Streicher-Porte M, Bader H-P, Scheidegger R, Kytzia S (2007) Material flow and economic analysis as a suitable tool for system analysis under the constraints of poor data availability and quality in emerging economies. Clean Technol Environ Policy 9(4):325-345

10. Kang H-Y, Schoenung JM (2006) Economic analysis of electronic waste recycling: modeling the cost and revenue of a materials recovery facility in California. Environ Sci Technol 40(5):1672-1680

11. Georgiadis P, Besiou M (2009) Environmental and economical sustainability of WEEE closed-loop supply chains with recycling: a system dynamics analysis. Int J Adv Manuf Technol 47(5-8):475-493

12. Renteria A, Alvarez E, Perez J, Pozo D (2010) A methodology to optimize the recycling process of WEEE: case of television sets and monitors. Int J Adv Manuf Technol 54(5-8):789-800

13. Schlummer M, Gruber L, Mäurer A, Wolz G, van Eldik R (2007) Characterisation of polymer fractions from waste electrical and electronic equipment (WEEE) and implications for waste management. Chemosphere 67(9):1866-1876

14. Maris E, Botané P, Wavrer P, Froelich D (2015) Characterizing plastics originating from WEEE: a case study in France. Miner Eng 76:28-37

15. Stevens GC, Goosey M (2008) Materials used in manufacturing electrical and electronic products. In: Electronic Waste Management. Royal Society of Chemistry, Cambridge, pp 40-74

16. Chancerel P, Rotter S (2009) Recycling-oriented characterization of small waste electrical and electronic equipment. Waste Manag 29(8):2336-2352

17. Lambert AJD (2003) Disassembly sequencing: a survey. Int J Prod Res 41(16):3721-3759

18. Penev KD, de Ron AJ (1996) Determination of a disassembly strategy. Int J Prod Res 34(2):495-506

19. Das S, Yedlarajiah P, Narendra R, Sanchoy K, Das P, Yedlarajiah, Narendra R (2000) An approach for estimating the end-of-life product disassembly effort and cost. Int J Prod Res 38(3):657-673

20. Ma Y-S, Jun H-B, Kim H-W, Lee D-H (2011) Disassembly process planning algorithms for end-of-life product recovery and environmentally conscious disposal. Int J Prod Res 49(23):7007-7027

21. Han HJ, Yu JM, Lee DH (2013) Mathematical model and solution algorithms for selective disassembly sequencing with multiple target components and sequence-dependent setups. Int J Prod Res 51(16):4997-5010

22. Tsai W, Hung S (2009) Treatment and recycling system optimisation with activity-based costing in WEEE reverse logistics management: an environmental supply chain perspective. Int J Prod Res 47(19):5391-5420 
23. González B, Adenso-Díaz B (2005) A bill of materials-based approach for end-of-life decision making in design for the environment. Int J Prod Res 43(10):2071-2099

24. Willems B, Dewulf W, Duflou JR (2006) Can large-scale disassembly be profitable? A linear programming approach to quantifying the turning point to make disassembly economically viable. Int J Prod Res 44(6):1125-1146

25. de Ron A, Penev K (1995) Disassembly and recycling of electronic consumer products: an overview. Technovation 15(6):363-374

26. Bream CE, Hornsby PR (2001) Comminuted thermoset recyclate as a reinforcing Part I Characterisation of recyclate feedstocks. J Mater Sci 36:2965-2975

27. Bream C, Hornsby P (2000) Structure development in thermoset recyclate-filled polypropylene composites. Polym Compos 21(3):417-435

28. Bream CE, Hornsby PR (2001) Comminuted thermoset recyclate as a reinforcing filler for thermoplastics-part II: structureproperty effects in polypropylene compositions. J Mater Sci 36:2977-2990

29. Gröning M, Eriksson H, Hakkarainen M, Albertsson AC (2006) Phenolic prepreg waste as functional filler with antioxidant effect in polypropylene and polyamide-6. Polym Degrad Stab 91(8):1815-1823

30. Dilhan M, Kalyon M, Hallouch, Fares N (1984) Recycling of thermosets as fillers. ANTEC 84:640-642

31. Cavalcante AP, Canto LB (2012) Use of industrial waste based on phenolic resin as filler for polypropylene. Polimeros 22(3):245-252

32. Chiang W-Y, Wu W-C, Pukánszky B (1994) Modification of polypropylene, blending with resole type phenol-formaldehyde resins. Eur Polym J 30(5):573-580

33. Cui L, Wang S, Zhang Y, Zhang Y (2007) Dynamically cured polypropylene/Novolac blends compatibilized with maleic anhydride-g-polypropylene. J Appl Polym Sci 104(5):3337-3346

34. Fu S-Y, Feng X-Q, Lauke B, Mai Y-W (2008) Effects of particle size, particle/matrix interface adhesion and particle loading on mechanical properties of particulate-polymer composites. Compos Part B Eng 39(6):933-961

35. Karger-Kocsis J (1995) Polypropylene: Structure, blends and composites

36. Móczó J, Pukánszky B (2008) Polymer micro and nanocomposites: structure, interactions, properties. J Ind Eng Chem 14(5):535-563

37. Waterman NA, Trubshaw R, Pye AM (1978) Filled thermoplastic materials part I: fillers and compounding. Mater Eng Appl. 1:74-79

38. Costa L, Rossi L, Di Montelera G, Camino ED, Weil, Pearce EM (1998) Flame-retardant properties of phenol-formaldehyde-type resins and triphenyl phosphate in styrene-acrylonitrile copolymers. J Appl Polym Sci 68:1067-1076

39. Seo K, Kim J, Bae J-Y (2006) Towards the development of thermally latent novolac-based char formers for ABS resins. Polym Degrad Stab 91(7):1513-1521

40. Hu X, Guo Y, Chen L, Wang X, Li L, Wang Y (2012) A novel polymeric intumescent flame retardant: synthesis, thermal degradation mechanism and application in ABS copolymer. Polym Degrad Stab 97(9):1772-1778

41. Lee K, Yoon K, Kim J, Bae J, Yang J, Hong S (2003) Effect of novolac phenol and oligomeric aryl phosphate mixtures on flame retardance enhancement of ABS. Polym Degrad Stab 81(1):173-179

42. Levchik SV, Bright DA, Alessio GR, Dashevsky S (2002) Synergistic action between aryl phosphates and phenolic resin in PBT. Polym Degrad Stab 77(2):267-272
43. Perrin D, Guillermain C, Bergeret A, Lopez-Cuesta J-M, Tersac G (2006) SMC composites waste management as reinforcing fillers in polypropylene by combination of mechanical and chemical recycling processes. J Mater Sci. 41(12):3593-3602

44. Palmer J, Ghita OR, Savage L, Evans KE (2009) Successful closed-loop recycling of thermoset composites. Compos Part A Appl Sci Manuf 40(4):490-498

45. Kouparitsas CE, Kartalis CN, Varelidis PC, Tsenoglou CJ, Papaspyrides CD (2002) Recycling of the fibrous fraction of reinforced thermoset composites. Polym Compos 23(4):682-689

46. Bruyère D, Simon S, Haas H, Conte T, Menad N-E (2016) Cryogenic ball milling: a key for elemental analysis of plastic-rich automotive shedder residue. Powder Technol 294:454-462

47. Gente V, La Marca F, Lucci F, Massacci P, Pani E (2004) Cryocomminution of plastic waste. Waste Manag 24(7):663-672

48. Schmidt J, Plata M, Tröger S, Peukert W (2012) Production of polymer particles below $5 \mu \mathrm{m}$ by wet grinding. Powder Technol 228:84-90

49. Hedayati M, Salehi M, Bagheri R, Panjepour M, Maghzian A (2011) Ball milling preparation and characterization of poly (ether ether ketone)/surface modified silica nanocomposite. Powder Technol 207(1):296-303

50. Molina-Boisseau S, Le Bolay N, Pons MN (2002) Fragmentation mechanism of poly(vinyl acetate) particles during size reduction in a vibrated bead mill. Powder Technol 123(2-3):282-291

51. Molina-Boisseau S, Le Bolay N (2000) Size reduction of polystyrene in a shaker bead mill-kinetic aspects. Chem Eng J 79(1):31-39

52. Jonna S, Lyons J (2005) Processing and properties of cryogenically milled post-consumer mixed plastic waste. Polym Test 24(4):428-434

53. Molina-Boisseau S, Bolay NL (2002) Characterisation of the physicochemical properties of polymers ground in a vibrated bead mill. Powder Technol 128(2):99-106

54. Kang H-Y, Schoenung JM (2005) Electronic waste recycling: a review of U.S. infrastructure and technology options. Resour Conserv Recycl 45(4):368-400

55. PlasticsEurope (2014) Automobile, Avec les plastiques, le monde bouge

56. Ausset S (2013) Procédé de recyclage de mélanges ABS-PC issus de déchets d'equipements électriques et électroniques (DEEE), vol 1. Université Bordeaux, Bordeaux

57. "DIRECTIVE 2002/95/CE DU PARLEMENT EUROPÉEN ET DU CONSEIL (2003) du 27 janvier 2003 relative à la limitation de l'utilisation de certaines substances dangereuses dans les équipements électriques et électroniques. J Off l'Union Eur

58. Ma C, Yu J, Wang B, Song Z, Xiang J, Hu S, Su S, Sun L (2016) Chemical recycling of brominated flame retarded plastics from e-waste for clean fuels production: A review. Renew Sustain Energy Rev 61:433-450

59. Chevalier M (1991) Phénoplastes ou phénols-formols. Tech. l'ingénieur

60. Miller R, Mark H, Gaylord N (1966) Phenolic resins. Encycl Polym Sci Technol 7(11):322-368

61. Tinke AP, Carnicer A, Govoreanu R, Scheltjens G, Lauwerysen L, Mertens N, Vanhoutte K, Brewster ME (2008) Particle shape and orientation in laser diffraction and static image analysis size distribution analysis of micrometer sized rectangular particles. Powder Technol.186(2):154-167

62. Bernardeau F, Perrin D, Caro-Bretelle A-S, Ienny P (2017) Valorization of waste thermoset material as a filler in thermoplastic: mechanical properties of phenolic molding compound waste filled PP composites. J Appl Polym Sci (accepted publication in progress, Oct. 2017) 